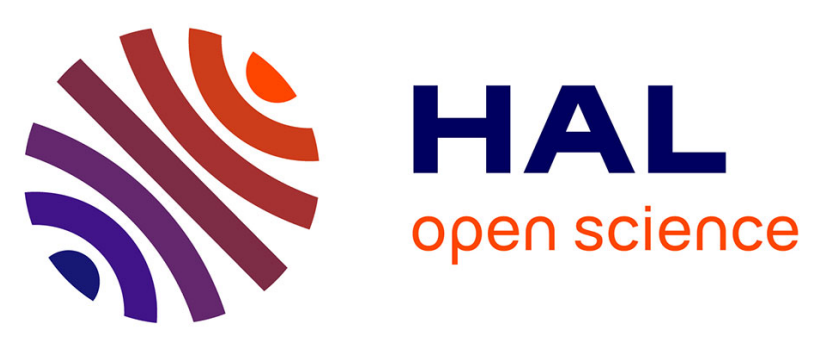

\title{
On the neural basis of sensory weighting: Alpha, beta and gamma modulations during complex movements
}

Nicolas Lebar, Jérémy Danna, Simon Moré, Laurence Mouchnino, Jean Blouin

\section{To cite this version:}

Nicolas Lebar, Jérémy Danna, Simon Moré, Laurence Mouchnino, Jean Blouin. On the neural basis of sensory weighting: Alpha, beta and gamma modulations during complex movements. NeuroImage, 2017, 150, pp.200 - 212. 10.1016/j.neuroimage.2017.02.043 . hal-01473866v2

\section{HAL Id: hal-01473866 https: / hal-amu.archives-ouvertes.fr/hal-01473866v2}

Submitted on 28 Feb 2017

HAL is a multi-disciplinary open access archive for the deposit and dissemination of scientific research documents, whether they are published or not. The documents may come from teaching and research institutions in France or abroad, or from public or private research centers.
L'archive ouverte pluridisciplinaire HAL, est destinée au dépôt et à la diffusion de documents scientifiques de niveau recherche, publiés ou non, émanant des établissements d'enseignement et de recherche français ou étrangers, des laboratoires publics ou privés. 


\title{
On the neural basis of sensory weighting: Alpha, beta and gamma modulations during complex movements
}

\author{
Nicolas Lebar, Jérémy Danna, Simon Moré, Laurence Mouchnino, Jean Blouin* \\ Aix Marseille Univ, CNRS, LNC, FR3C 3512, Marseille, France
}

\section{A R T I C L E I N F O}

\section{Keywords:}

Arm movement

Sensory conflict

Vision

Proprioception

Electroencephalography

Event-related desynchronization

\begin{abstract}
A B S T R A C T
Previous studies have revealed that visual and somatosensory information is processed as a function of its relevance during movement execution. We thus performed spectral decompositions of ongoing neural activities within the somatosensory and visual areas while human participants performed a complex visuomotor task. In this task, participants followed the outline of irregular polygons with a pen-controlled cursor. At unpredictable times, the motion of the cursor deviated $120^{\circ}$ with respect to the actual pen position creating an incongruence between visual and somatosensory inputs, thus increasing the importance of visual feedback to control the movement as suggested in previous studies. We found that alpha and beta power significantly decreased in the visual cortex during sensory incongruence when compared to unperturbed conditions. This result is in line with an increased gain of visual inputs during sensory incongruence. In parallel, we also found a simultaneous decrease of gamma and beta power in sensorimotor areas which has not been reported previously. The gamma desynchronization suggests a reduced integration of somatosensory inputs for controlling movements with sensory incongruence while beta ERD could be more specifically linked to sensorimotor adaptation processes.
\end{abstract}

\section{Introduction}

Our capacity to allocate resources to relevant sensory information is a central tenet in establishing proper and safe interactions with our environment. According to prevailing theories of motor control, this would involve increasing feedback gains of pertinent sensory inputs and decreasing the gains of irrelevant sensory inputs (e.g., Ernst and Banks, 2002; Scott, 2004; Todorov and Jordan, 2002). This theoretical assumption has received considerable support from studies in which human participants performed goal-directed movements with incongruent visual and somatosensory feedback (Rossetti et al., 1995; Sarlegna and Sainburg, 2007; Sober and Sabes, 2003). Seeing our hand movements through a mirror or moving a cursor with a computer mouse are examples of experimental contexts where the mapping between these sensory inputs is altered. Consistent with sensory gain control theories, Bernier et al. (2009) found that the amplitude of evoked potentials recorded in the somatosensory cortex following median nerve stimulation (SEP) is substantially smaller when drawing with mirror-reversed vision compared to normal vision. This reduction in SEP amplitude was interpreted as a result of the functional downweighting of proprioceptive inputs to facilitate movement performance during sensory conflict (Balslev et al., 2004; Bernier et al., 2009; Lajoie et al., 1992). Evidence for visual information up-regulation has also been suggested for movements performed with mirror-reversed vision, as participants who had more accurate tracing movements showed greater sensitivity to visual inputs compared to their less accurate counterparts (Lebar et al., 2015).

To date, the neural mechanisms underlying the weighting of afferent inputs when controlling movements with incongruent visual and somatosensory feedback are poorly understood. We set out to shed light on this issue by investigating neural oscillations within the visual and somatosensory cortices in humans. Our approach builds on the current consensus that functional processing of sensory inputs is associated with distinct band-specific neural oscillations within the cerebral cortex. For instance, alpha oscillations $(\sim 8-12 \mathrm{~Hz})$ are considered to be a local marker of the level of excitability of the somatosensory and visual cortices, with a smaller alpha power being associated with greater excitability (Anderson and Ding, 2011; Pfurtscheller and Lopes da Silva, 1999). The power of alpha is therefore thought to be lowest when sensory inputs are task-relevant (e.g. Haegens et al., 2011; Zumer et al., 2014). On the other hand, beta oscillations $(\sim 15-25 \mathrm{~Hz})$ predominate during unchanged states (or status quo) of the sensorimotor cortex and largely decrease prior to ( $\sim 1-2 \mathrm{~s})$ and during movements. Therefore, beta desynchronization in the somatosensory cortex is classically associated with the processing, or preparation to process, somatosensory inputs (Cheyne et al., 2003;

\footnotetext{
* Correspondence to: Laboratory of Cognitive Neuroscience, Aix-Marseille University, 3, Place Victor-Hugo, 13331 Marseille, France.

E-mail address: jean.blouin@univ-amu.fr (J. Blouin).
} 
Pfurtscheller and Lopes da Dilva, 1999; van Ede et al., 2011, 2012). From a functional point of view, the power of alpha and beta has been found to be inversely related to sensory detectability and discriminability (Ergenoglu et al., 2004; Hanslmayr et al., 2007; Romei et al., 2010; van Dijk et al., 2008), and also to the speed of visual and motor information processing (Pogosyan et al., 2009; Thut et al., 2006; Zhang et al., 2008). In this light, the co-modulation of alpha and beta power might provide an efficient mechanism to contextually weight visual and somatosensory inputs, according to their relevance, during movement control.

Contrary to alpha and beta oscillations, gamma oscillations (> $30 \mathrm{~Hz}$ ) increase in the visual and somatosensory cortices during visual and proprioceptive stimulation. Gamma power is therefore frequently reported as being negatively correlated with the alpha and beta power (Pfurtscheller et al., 2003, Tallon-Baudry and Bertrand, 1999). Contributing to a higher level of sensory information processing, gamma oscillations are considered as neural markers of unimodal and multimodal sensory binding (Engel et al., 2012; Ghazanfar et al., 2008; Krebber et al., 2015; Maier et al., 2008; Wang, 2010). For instance, gamma response in the occipital cortex is observed following the presentation of two coherent visual stimuli (Tallon-Baudry et al., 1996; Zarka et al., 2014). This response is absent when a visual stimulus is presented simultaneously with incongruent visual (TallonBaudry et al., 1996; Zarka et al., 2014) or non-visual stimuli (Ghazanfar et al., 2008; Krebber et al., 2015; Maier et al., 2008). In the case of incongruent visuo-tactile stimulation, this decrease of gamma power is not only observed over the visual cortex but is also found centrally, over the somatosensory cortex (Krebber et al., 2015). These latter findings are also consistent with the suggestion that gamma oscillations serve to connect neural populations that encode stimuli of different sensory modalities (Fries, 2009; Wang, 2010).

Examination of the spectral content of cortical neural oscillations therefore suggests that multiple flexible mechanisms could intervene to dynamically weight sensory information during movements. However, two important points emerge from the literature that currently precludes drawing firm conclusions regarding these mechanisms. First, current assumptions on the link between neural oscillations and sensory re-weighting primarily derive from studies in which the sensory inputs were task-irrelevant (e.g., Krebber et al., 2015) or relevant for non-motor processes (e.g., visual, tactile or pain perception, see Tallon-Baudry et al., 1996; Bauer et al., 2006). Second, in studies targeting sensorimotor processes, neural oscillations were principally assessed either during the planning phase of the movements or during discrete motor actions of short duration (e.g., < $1 \mathrm{~s}$; Chung et al., 2017; Thürer et al., 2016; Torrecillos et al., 2015).

In the present study, we investigated the mechanisms underlying feedback gain modulation by assessing the oscillatory activity of the visual and somatosensory cortices when individuals controlled their movements with either a congruence or incongruence between visual and somatosensory feedback. Importantly, exposure to the sensory incongruence was set to be sufficiently long (i.e., $\sim 6-10 \mathrm{~s}$ for each trial) to allow this assessment during the movement itself (rather than before or after movement). Based on the conclusions of previous studies (i.e., Balslev et al., 2004; Bernier et al., 2009; Lajoie et al., 1992; Lebar et al., 2015), we hypothesized that there would be an increased gain of visual feedback and a decreased gain of somatosensory information when the two modalities become incongruent during movement. Specifically, in the visual cortex, we expected that there would be an increase in alpha and beta desynchronization, as well as a synchronization of gamma. In contrast, in the somatosensory cortex, we predicted that there would be a synchronization of alpha and beta frequency bands and a desynchronization of gamma activity.

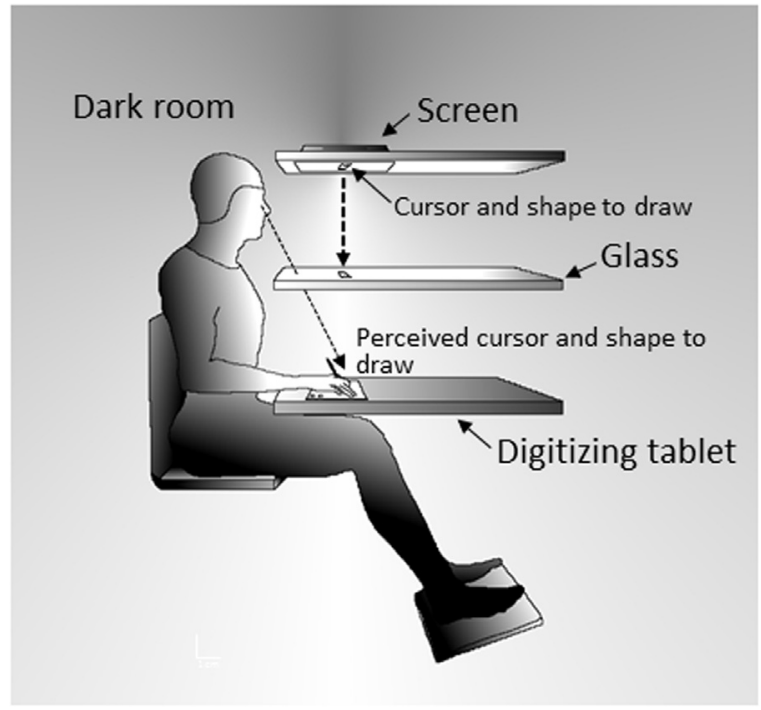

Fig. 1. Experimental set-up. Participants had to follow as precisely as possible the outline of a two-dimensional shape with a cursor controlled by the tip of a digitizing pen held in their right hand. Because of the equal distance between the screen, the glass and the tablet, participants perceived the cursor and the shape at the hand level. The room was dark and the glass prevented the direct vision of the drawing hand.

\section{Materials and methods}

\section{Participants}

Eighteen right-handed participants, aged between 22 and 38 years old (mean: $26 \pm 4$ yrs (SD), 10 females, 8 males) participated to the experiment which lasted $\sim 1 \mathrm{~h} 45$. They all signed informed consent documents prior to the experiment, and were paid for their participation to the study. Prior to participation, the participants underwent the Edinburgh Handedness Inventory 2 test to ensure that they were righthanded. A score of zero to this test indicates no preference for either hand while a score of 100 or -100 reveals a maximal preference for the right or left hand, respectively. The participants' scores ranged between 20 and 100 (mean $79 \pm 25$ (SD)). All protocols and procedures were in accordance with the 1964 declaration of Helsinki.

\section{Apparatus and stimuli}

A schematic representation of the experimental set-up is shown in Fig. 1. The set-up was structured in 3 levels: a top level with a computer screen oriented downward, a mid-level with a semi-reflecting glass and a lower level with a digitizing tablet laid on a table. The glass was positioned at an equal distance between the screen and the digitizing tablet. With this configuration, the images projected by the screen appeared as virtual images on the digitizing table. As a panel prevented direct vision of the screen and because the experimental set-up was located in a dark chamber, these virtual images were the only visual information that the participants could see.

The participants' task was to follow, as precisely as possible, the outline of two-dimensional shapes with a cursor controlled by the tip of a digitizing pen held in their right hand. Visual feedback of the tip of the pen was provided by a 3-mm white dot. The presentation of visual stimuli and the collection of hand trajectories were controlled using custom MATLAB (Mathworks) program and the Psychophysics toolboxes (Brainard, 1997; Pelli, 1997). Six different irregular white polygons were used (Fig. 2A shows one of them). These shapes were displayed on a black background and consisted of 10 thin $(1 \mathrm{~mm})$ straight lines (10 angles) whose lengths varied between $31-90 \mathrm{~mm}$. The total perimeter was $186 \mathrm{~mm}$ for all shapes. 

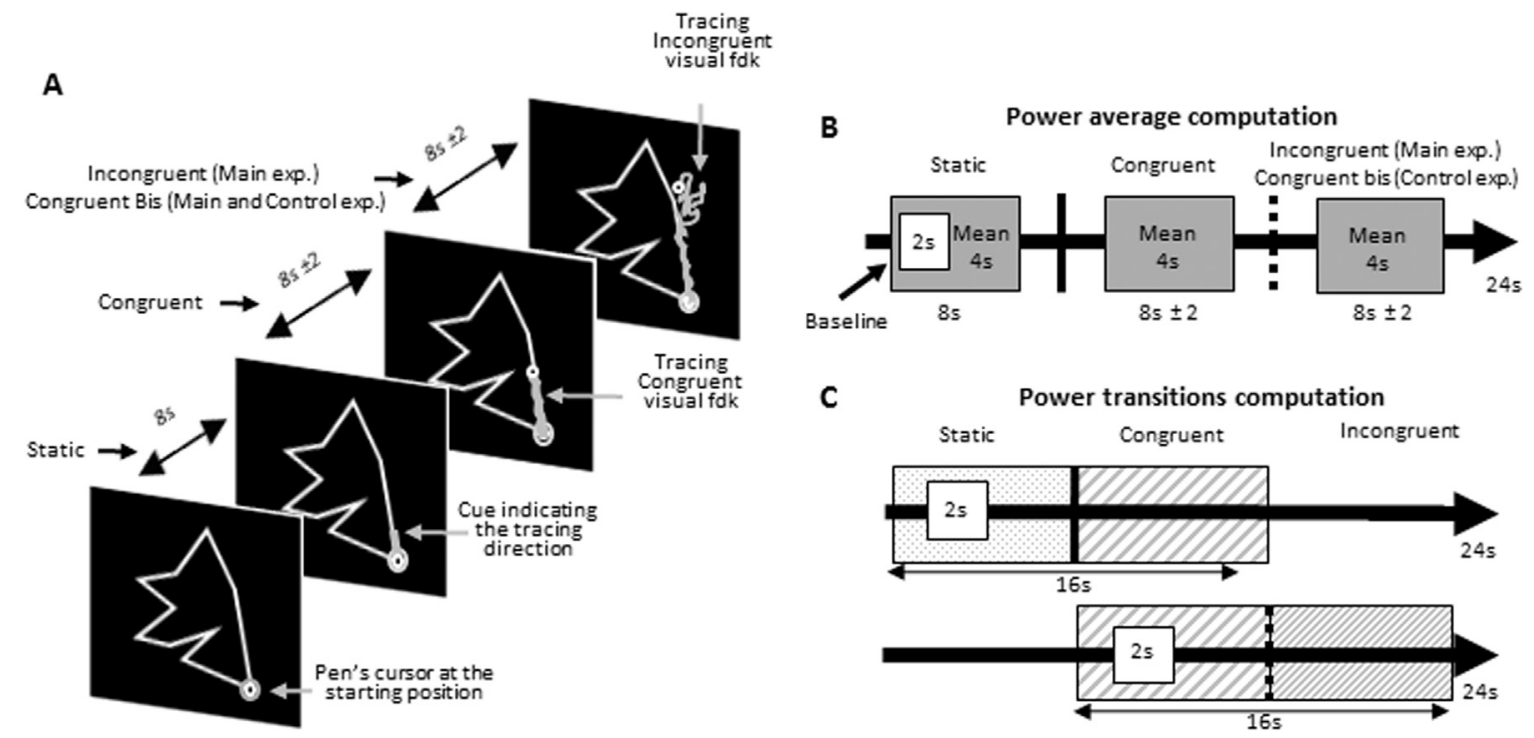

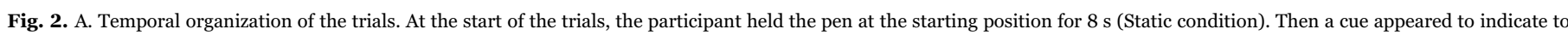

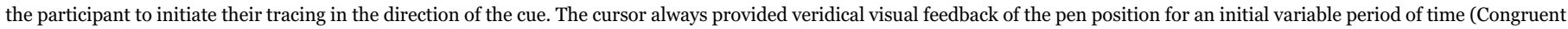

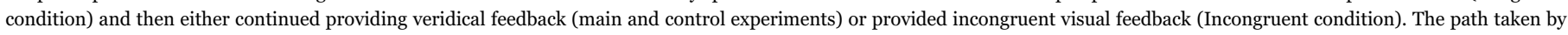

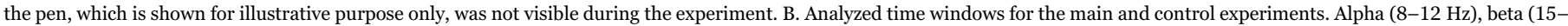

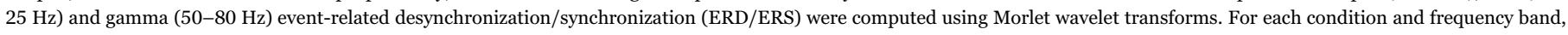

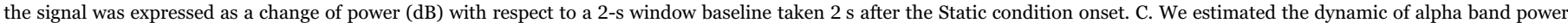

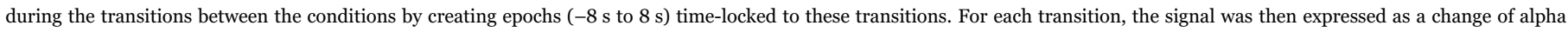
power $(\mathrm{dB})$ with respect to its own baseline.

\section{Experimental task}

\section{Main experiment}

The temporal organization of the trials is depicted in Fig. 2A. Each trial started with the presentation of a shape and the pen cursor. At this time, the participants had to bring the cursor to the starting position. This position was indicated by a red circle positioned at a randomlyselected angle of the polygon. Then, $8 \mathrm{~s}$ after hearing a preparatory beep signal, a portion (i.e., $7 \mathrm{~mm}$ ) of the polygon adjacent to the starting point turned green. This served as a go signal to start tracing the shape in the direction of the green segment. Hereafter, the 8speriod between the preparatory and go signals will be referred to as the Static condition. For a random period of time (i.e., $8 \mathrm{~s} \pm 2$ ), the cursor provided veridical visual feedback of the tip of the pen (period referred to as the Congruent condition). After this time and until the end of the trial (i.e., $8 \mathrm{~s} \pm 2$ ), the cursor either continued to provide veridical visual feedback (24 trials) or deviated $120^{\circ}$ clockwise or counterclockwise (24 trials for each direction) with respect to the actual pen position (hereafter called Incongruent condition). In this latter condition, with altered visual feedback of the pen, the information carried by visual and somatosensory signals became incongruent, thereby increasing tracing difficulty (Balslev et al., 2004; Gagné-Lemieux et al., 2014; Lajoie et al., 1992). The angle of $120^{\circ}$ was chosen based on pilot experiments, as this angle was the most difficult for participants to rapidly adapt to the sensory incongruence. Participants were instructed that if the pen's cursor left the polygon, they had to bring the cursor back to the point where it left the polygon before continuing tracing the contour of the shape. For both the behavioral and electrophysiological analyses, we pooled trials with clockwise and counterclockwise cursor deviations in a single Incongruent condition composed of 48 trials. The duration of both the Congruent and Incongruent conditions (i.e., $8 \mathrm{~s} \pm$ 2) was sufficiently long for investigating the neural strategies (i.e. change of frequency-band power) when participants controlled their movements with either normal or perturbed visual feedback (see below for the time windows used to compute alpha, beta and gamma eventrelated desynchronization (ERD) /synchronization (ERS)). The duration of each condition (i.e., Static, Congruent, Incongruent) was set such that each trial lasted $24 \mathrm{~s}$.

In all conditions, the participants had to keep their gaze on the cursor. In the tracing conditions, fixation on the pen constituted natural behavior, thus none of the participants reported any difficulties complying with these instructions. Participants were also asked to stay as relaxed as possible after reaching the starting position and to produce only the minimal force that was needed to move the pen. They were instructed not to contract face, left arm and leg muscles. In both the Congruent and Incongruent conditions, the participants were asked to produce slow tracing movements to minimize contamination of the EEG signals by fast pursuit eye movements and large activation of arm muscles during tracing. An experimenter gave a demonstration of acceptable tracing speeds prior to the experimental session (offline analyses yielded a mean tracing velocities of $2.45 \mathrm{~mm} / \mathrm{s}$ ). The experimenter also verified that the participants complied with this velocity requirement using the tracing feedback on a computer screen. Corrective instructions were provided between trials when necessary.

The present study aims at investigating the neural processes implemented when movements are controlled with incongruent somatosensory and visual feedback. Motor performance, during repetitive exposure to a sensory conflict, can return to pre-exposure level quickly (e.g., only 15 trials in Sarlegna et al., 2007). Our experimental paradigm was therefore built in order to limit participants' adaptation to their novel sensory environment. This was particularly important for ensuring a good representativeness of the condition-averaged data (see below). Thus, to maintain tracing difficulty to a high level during the exposure to the sensory incongruence, (1) participants had to trace 6 different shapes which were randomly presented, (2) both the starting position and the tracing direction (i.e., clockwise or counterclockwise) changed for each presentation of a given shape, (3) the presentation of the Incongruent $120^{\circ}$ and Incongruent $-120^{\circ}$ conditions was pseudorandomly presented alongside trials without sensory incongruence. Moreover, in order to reduce the participants' possibility to anticipate the sensory incongruence, the Incongruent conditions occurred only in two-thirds of the trials (i.e., 48 out of 72 trials) and started at a random period of time $(8 s \pm 2)$ after the Congruent condition onset. 


\section{Control experiment}

In the protocol described above, the Incongruent condition always occurred after both the Static and Congruent conditions (i.e., $\sim 18 \mathrm{~s}$ after the preparatory beep signal). This ordering of the experimental conditions raises the possibility that any change of frequency power observed in the Incongruent condition could have resulted from uncontrolled time-related effects. However, the small number of trials without sensory incongruence (i.e. 24) in the main experiment makes it difficult to perform any accurate comparisons between the initial and later tracing movements. (for comparison, the analyses pertaining to the Incongruent condition were performed with 48 trials, see below). Thus, we conducted an additional experiment with 50 trials wherein participants traced the polygons only with veridical visual feedback of the pen's position to specifically control for potential time-related effects.

Twelve right-handed participants were recruited for this control experiment. They were aged between 22 and 32 years old (mean age 27 \pm 4 yrs (SD), 6 females) and were paid for their participation. Six of them also participated to the main experiment. All participants underwent the Edinburgh Handedness Inventory2 test (see above for details). They all showed a right hand preference with scores between 47 and 100 (mean $86 \pm 23$ (SD)). Each participant signed an informed consent. All procedures and protocols were in accordance with the 1964 Helsinki declaration and approved by the local Ethics Committee.

The set-up and procedure (including trial durations) were the same as in the main experiment. The only difference was that for all trials (i.e., 50), the Static and the Congruent conditions were followed by a second period of tracing with congruent feedback. Hereafter, this latter time period will be referred to as Congruent-bis condition (see Fig. 2A).

\section{Data recordings and reduction}

\section{Behavior}

Data from the digitizing tablet (Wacom Intuos 4, spatial resolution $5080 \mathrm{lpi}$ ) were recorded in text format for each participant. We extracted for each time point the $\mathrm{x}$ and $\mathrm{y}$ spatial coordinates of the cursor on the screen (resolution $1280 \times 768$, refresh rate: $160 \mathrm{~Hz}$ ). We also saved the spatial coordinates of the shape used for each trial. These data were stored for off-line analyses.

Tracing performance in the Congruent and Incongruent conditions was assessed using three criteria: (1) the distance error index, which was defined as the ratio between the total distance covered by the digitizing pen and the total length of all drawn segments. The closer this error index is to 1 , the more efficient the participant was at tracing (an index of 1 indicating perfect tracing); (2) the radial error index, which was calculated by first computing the shortest radial distance between each point of the tracing trajectory and the polygon and then by averaging the radial distance obtained over the total duration of the trials; (3) Although it was constrained and controlled by the experimenter, we also computed and analyzed the average speed of the tracing as it could potentially affect neural oscillations (e.g., gamma power could increase in the occipital cortex with speed of the visual stimulus, Gray et al., 1997; Ofori et al., 2015). The distance and radial error indices provided estimates of the spatial accuracy of the tracings while the average speed provided information regarding the dynamical features of the tracing movements.

\section{Electroencephalography (EEG)}

Electroencephalographic (EEG) signals were recorded continuously from 64 pre-amplified $\mathrm{Ag} / \mathrm{AgCl}$ electrodes (Active-two-Biosemi) embedded on an elastic cap in accordance with the extended 10/20 system. Specific to the Biosemi system, the ground electrode was replaced with two separate electrodes, a Common Mode Sense (CMS) active electrode and a Driven Right Leg (DRL) passive electrode. These 2 electrodes, located near Pz and POz electrodes, form a feedback loop, which drives the average potential of the subject (the Common Mode voltage) as close as possible to the analog-digital converter (ADC) reference voltage in the AD-box. The EEG signals were digitized at a sampling rate of $2048 \mathrm{~Hz}$ (DC low pass filter $400 \mathrm{~Hz}, 3 \mathrm{~dB} /$ octave) and saved for off-line analyses.

Off-line data preprocessing and analyses were performed using EEGLAB Matlab (Delorme and Makeig, 2004) and FieldTrip (Oostenveld et al., 2011). The EEG recordings were re-referenced to the average signals of both mastoid electrodes except for one participant for whom the right mastoid was used as a reference because of the high level of noise on the other electrode. $50 \mathrm{~Hz}$ (AC sector) and $160 \mathrm{~Hz}$ (screen refresh rate) frequencies were removed from the signals (bandwidth: $1 \mathrm{~Hz}$ ) using the frequency-domain regression technique implemented in the EEGlab cleanline tool. Ocular artifacts (e.g., blinks, saccades) were subtracted from the EEG recordings by removing the corresponding component as revealed by the independent component analyses (ICA). We then applied a spatial filter (surface Laplacian, Perrin et al., 1989; order term of the Legendre polynomial=10, smoothing $=1 \mathrm{e}-5, \mathrm{~m}=4$ ) thereby increasing the topographical selectivity by filtering out volume-conducted potentials. This surface Laplacian filter estimates the potential at the dura, increasing the spatial resolution of the data from $\sim 10 \mathrm{~cm}$ to $\sim 2 \mathrm{~cm}$ (Law et al., 1993; Nunez, 2000). It also allows reducing muscular artifacts (Fitzgibbon et al., 2013), particularly when cortical sources are from relatively small generators (Nunez and Srinivassan, 2006), as is the case for higher-frequency sources (Crone et al., 1998).

We created epochs of $8 \mathrm{~s}$ time-locked at the onset $(0 \mathrm{~s}$ to $8 \mathrm{~s})$ of either the Static, Congruent (i.e. movement onset), Incongruent, and Congruent-bis conditions (the latter for the control experiment). Epochs were then visually inspected and those still presenting artifacts were rejected. On average, we kept 45 (out of 48) epochs per condition.

We computed alpha (8-12 Hz), beta (15-25 Hz) and gamma (50$80 \mathrm{~Hz}$ ) event related desynchronization/synchronization (ERD/ERS) using Morlet wavelet transforms relative to a $2 \mathrm{~s}$ window baseline in the Static condition (from $2 \mathrm{~s}$ to $4 \mathrm{~s}$, see Fig. 2B). Higher gamma-bands (i.e., $>80 \mathrm{~Hz}$ ) were not analyzed in the current study because they are known to only transiently change during motor execution and are therefore associated with movement planning and initiation rather than continuous movement execution (Crone et al., 1998). The signals were expressed, for each condition and for each frequency band, as a change of power (dB) with respect to this baseline. We addressed the time/frequency trade-off issue of the frequency analyses by choosing to enhance the spectral precision of the analyses at the expense of their temporal precision. We thus employed a relatively high number of wavelet cycles (cycles $=7$, step $=0.5 \mathrm{~Hz}$ ). For each participant and analyzed electrode (see below), we then extracted the power average from $4 \mathrm{~s}$ windows (from $2 \mathrm{~s}$ to $6 \mathrm{~s}$ in the $8 \mathrm{~s} \pm 2$ segments) for each condition (Static, Congruent, Incongruent). This temporal window allows to include several oscillations cycles, thereby increasing the signal-to-noise ratio which tends to be low for higher-frequency activity (Cohen, 2014). We purposely selected time windows (baseline and analyzed windows) that were away (2 s) from conditions' onsets. This allowed (1) to avoid neural activity related to the transition between the different conditions (which might include activity related to the element of surprise introduced by the biased visual feedback) and, (2) to prevent edge effects (or cone of influence) as wavelet coefficients are less accurate at the beginning and end of the time series (Cazelles et al., 2008; Torrence and Compo, 1998). This ensured that each time window provided a representative picture of the neural mechanisms in each sensory condition.

In order to obtain an estimation of the dynamic of the band power activity during the transitions between the conditions, we created new epochs of $16 \mathrm{~s}$ time-locked to these transitions ( $-8 \mathrm{~s}$ to $8 \mathrm{~s}$ ). The epochs time-locked to movement onset allowed analyzing band power during the transition between Static and Congruent conditions. The epochs time-locked to the onset of the Incongruent condition permitted investigating the transition between the Congruent and Incongruent 
conditions. After visual inspection of the epochs and rejection of those still presenting artifacts, 57 epochs (out of 72) remained for the Static/ Congruent transition and 42 epochs (out of 48) remained for the Congruent/Incongruent transition.

For each trial, we then performed ERD/ERS transforms with Morlet wavelet from a $2 \mathrm{~s}$ baseline taken from the condition preceding the transition (from $-6 \mathrm{~s}$ to $-4 \mathrm{~s}$, see Fig. 2c). These analyses were performed on the EEG sources of each frequency band in order to maximize their temporal and spatial resolution. The frequency-band power was averaged at each time point for each electrode of interest, first for each participant, and then across participants for visual assessments.

Source analyses. To estimate the topography of alpha, beta, and gamma ERD/ERS resulting from the transitions between conditions, we computed electrophysiological sources using the minimum norm algorithm as implemented in Brainstorm software (Tadel et al., 2011). This algorithm provides a solution for the "ill-posedness" of the inverse problem by introducing a regularizer or prior in the form of a source covariance that favors solutions that are of minimum energy. This requires specification of a noise and a source covariance matrix that we estimated directly from recordings. All mathematical details of the algorithm are fully described in Hämäläinen (2009). The algorithm was applied on the preprocessed data. Then, we estimated the localization of the activity in the source space, for each participant and each frequency-band using Hilbert transform. Afterwards, we normalized the activity relative to the baseline period, i.e. from -6 to -4 s prior to the onset of each transition (i.e., from Static to Congruent and from Congruent to Incongruent) before averaging the power of each frequency over a 2-6s windows post transition. This normalization corresponds to the synchronization (ERS)/desynchronization (ERD) transformation. In a group analysis, we then compared the averaged value against 0 and projected the result (significant t-values) on a widely used standard for multi-subject anatomical analyses (Colin 27 from the Montreal Neurological Institute, 8000 vertices).

\section{Electrooculography (EOG)}

Electrooculographic (EOG) activity was recorded with surface electrodes placed near the right outer canthus and under the right orbit. The EOG recording was used to monitor the number of blinks and saccades and to reduce EEG artifacts related to these ocular events (see ICA method above). The EOG signals were also digitized at a sampling rate of $2048 \mathrm{~Hz}$ (DC low pass filter $400 \mathrm{~Hz}, 3 \mathrm{~dB} /$ octave).

The EOG signals were then visually inspected and the number of blinks and saccades was counted to control whether the participants succeeded at fixating on the cursor in both the Congruent and Incongruent conditions.

\section{Statistics}

\section{Behavior}

We first determined whether tracing performance was altered when participants controlled their movements with incongruent somatosensory and visual feedback. This was done by comparing using paired ttests the mean values obtained for each participant and behavioral variable (i.e., distance and radial error indices, average speed) in the Congruent and Incongruent conditions.

We also performed specific analyses to determine the degree to which participants adapted to their novel sensory environment in the Incongruent condition despite the fact that the present study was built to minimize adaptation to the sensory incongruence. These analyses consisted of comparing, for each performance index, the average scores obtained in the first and last 10 trials in both the Congruent and Incongruent conditions using 2 (Condition: Congruent, Incongruent) $\mathrm{x}$
2 (Trial: First 10, Last 10) ANOVAs.

For all tests, we report the $p$ (alpha level was set at 0.05 ) and $T$ or $F$ values, as well as the size effects (Cohen's $d$ ). The size effect was calculated using the formula:

$d=($ mean $\mathrm{B}-$ mean $\mathrm{A}) /(\mathrm{SD}[\mathrm{AB}])$

With this method, $d$ values of $0.2,0.5$ and 0.8 are considered to represent small, medium and large effect sizes, respectively (Cohen, 1988).

\section{$E E G$}

We used separate cluster-based permutation tests (Maris and Oostenveld, 2007) to compare the power of alpha, beta, and gamma frequency bands between the Congruent and the Static conditions, and between the Incongruent and Congruent conditions. These analyses are appropriate when data distributions violate the normality assumption as in the present study (confirmed by Shapiro-Wilks tests). Importantly, compared to the analyses performed on individual electrodes, this non-parametric test has an advantage in dealing with mass-univariate analyses (i.e., multiple comparisons) which might increase Type 1 errors (also termed family-wise error rate). Indeed, cluster-based permutation tests take into account the dependencies present in the signals (in both temporal and spatial dimensions), and correct for them (Maris and Oostenveld, 2007; Pernet et al., 2015). The permutation test is therefore highly relevant in the context of the present study, given the large number of electrodes that overlay the sensorimotor and visual cortices (e.g., respectively 7 and 8 electrodes, for the sensorimotor and occipital cortices according to the Koessler et al.'s (2009) simultaneous EEG-MRI study). 5000 permutations were performed to compute the Monte Carlo $p$ value and to reveal significantly different clusters $(\mathrm{p}<.05)$ over the scalp between paired conditions, for each frequency-band.

The cluster-based permutations tests used all recorded EEG channels. However, we will focus our analyses on clusters of the topographical maps overlying the somatosensory and occipital cortices. These regions were those where task-relevant modulations of sensory inputs have been found in previous studies (see: Introduction) and where we predicted changes of power in the different frequency-bands in the Incongruent condition.

\section{EOG}

We separately submitted the number of blink and saccade distributions to paired t-tests to compare the ocular behavior in Congruent and Incongruent conditions.

\section{Results}

\section{Tracing performance}

As expected, participants accurately traced the shapes with congruent visual/somatosensory feedback and their performance was impaired when tracing in the Incongruent condition (Fig. 3A). This was confirmed by the t-tests that showed that both the distance error index and the radial error index were significantly greater in the Incongruent condition compared to the Congruent condition $(\mathrm{p}<.002$, $\mathrm{t}(17)=-3.75, d=1.07$ and $\mathrm{p}<.001, \mathrm{t}(17)=-5.96, d=1.38$ for the distance and radial errors respectively). On the other hand, tracing speed was significantly faster, although very marginally, when participants performed their movements in the Incongruent condition $(2.3 \mathrm{~mm} / \mathrm{s}$ (Congruent) vs $2.6 \mathrm{~mm} / \mathrm{s}$ (Incongruent), $p<.007, t(17)=-3.07)$. This small increase of tracing speed (Cohen's $d=0.32$ ), might reflect the participants' wish to promptly bring the pen's cursor to the point where it left the polygon when deviating from it. The increase in speed could have also resulted from a desire to increase the amount of experience (by increasing the number of movements) during the exposure to the sensory incongruence in order to adapt to it, although such actions 

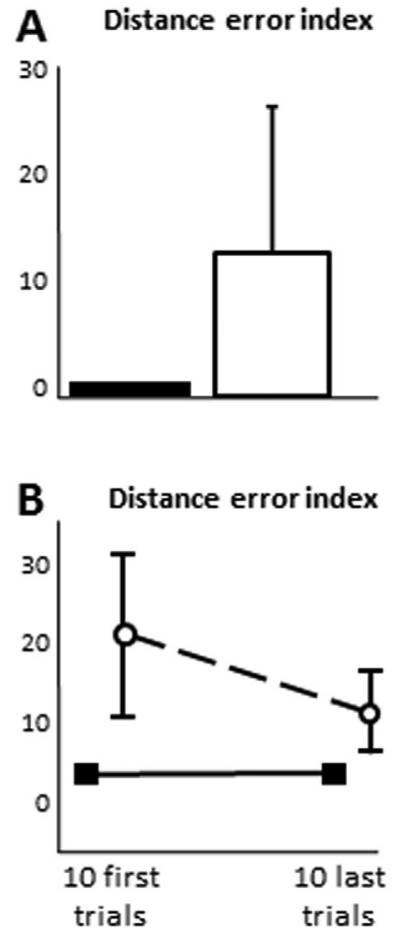

Radial error index

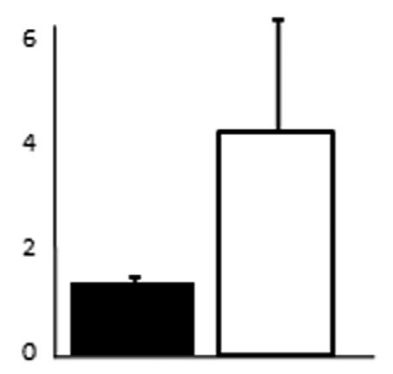

Radial errorindex

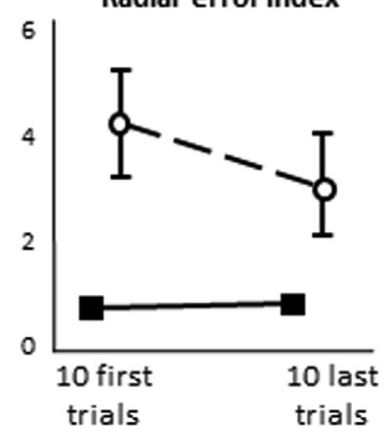

Speed $(\mathrm{mm} / \mathrm{s})$

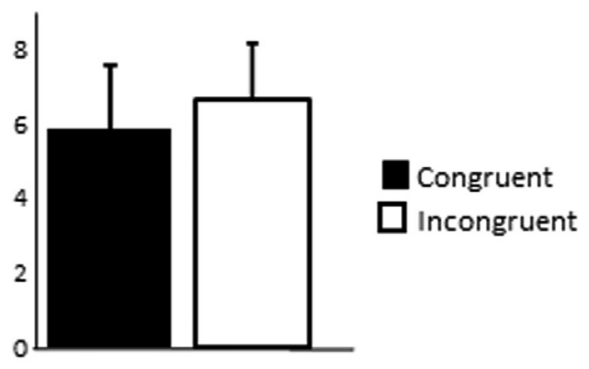

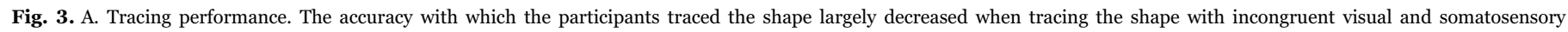

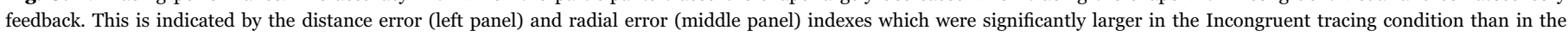

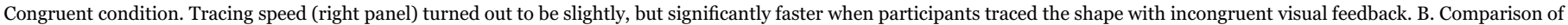

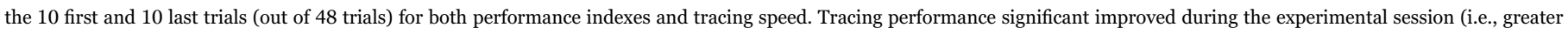

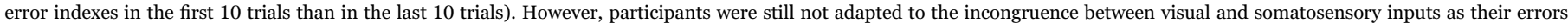

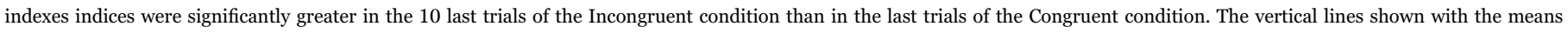
represent between-subject standard deviations (for the error indexes, the standard deviations computed in the Congruent condition were too small to be seen in the graphs).

\section{Congruent minus \\ Static \\ (Main exp.)

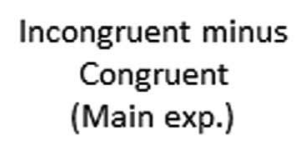

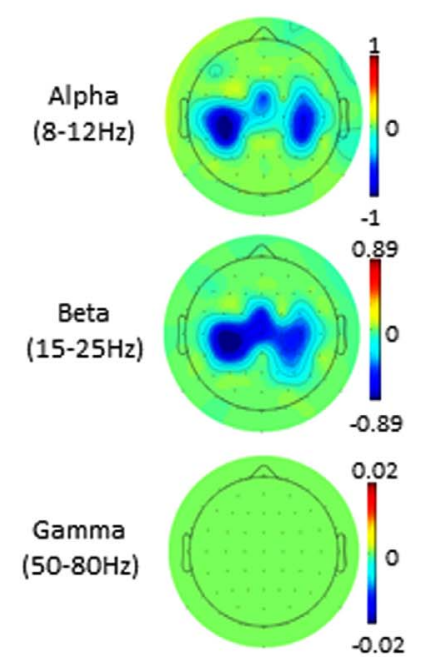
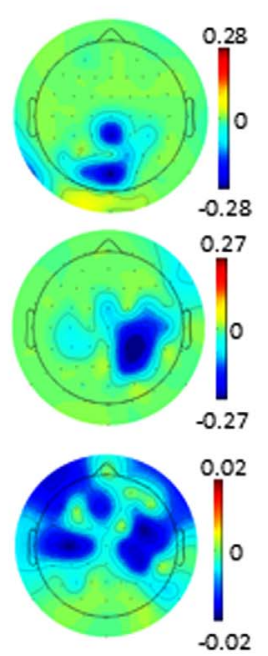

Congruent-bis minus Congruent (Control exp.)

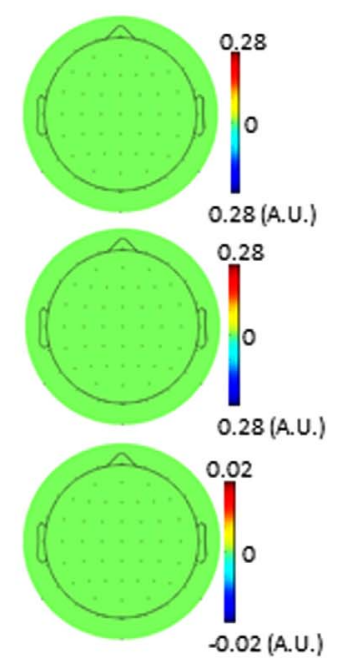

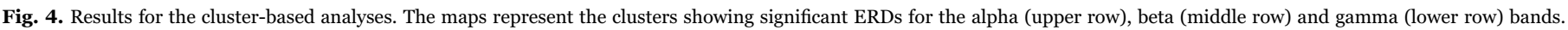

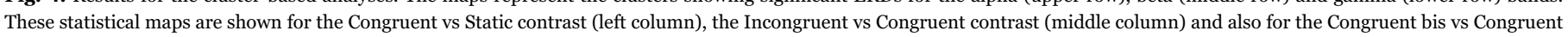

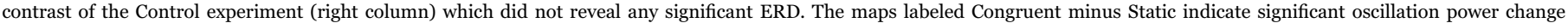

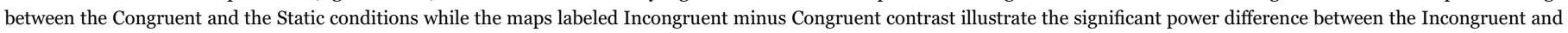
Congruent conditions.

were both discouraged by the task instructions.

Comparing the motor behavior in the first and last 10 trials of the Congruent and Incongruent conditions revealed some improvement in tracing performance with repetitive exposure to the novel sensory environments (Fig. 3B). This was attested by ANOVAs showing significant Condition $\times$ Trial interactions for both the distance error index $(F(1,17)=7.14, p<.02)$ and the radial error index $(F(1,17)$ $=19.94, p<.001)$. The decomposition of the interactions revealed that, 
tracing performance between the first and last 10 trials in the Congruent condition were not significantly different; but both error indices significantly decreased between the first and last 10 trials in the Incongruent condition ( $d=1.04$ and 1.53 for the distance and radial error index, respectively). However, the mean distance and radial index errors computed in the Incongruent condition were still significantly larger (large effect sizes according to Cohen's $d$ ) in the last 10 trials than in the last 10 trials of the Congruent condition $(\sim 7$ and $\sim 3$ times larger, $d=0.97$ and $d=1.27$ respectively Fig. 3B).

With regard to tracing speed, there was neither a significant effect of Trial nor a significant Condition $x$ Trial interaction $(p>0.05)$. However, there was a significant main effect of Condition; the tracing speed was significantly faster in the Incongruent compared to the Congruent conditions $(\mathrm{F}(1,17)=14.62, \mathrm{p}<.005, d=0.32)$.

Overall, the behavioral analyses indicate that, despite some improvement with exposure to the task and repetition, tracing performance was still largely impaired at the end of the experimental session for movements with incongruent visual/somatosensory feedback. Thus, these results provide important behavioral bases for comparing the spectral content of cortical neural oscillations between conditions with and without sensory incongruence.

\section{Electrophysiological data -cluster-based permutation test}

Results of the permutation tests of the main and control experiments are shown in the topographical maps of Fig. 4. These statistical maps depict the significant clusters in the alpha, beta, and gamma frequency-bands for both contrasts (i.e., Congruent minus Static conditions, Incongruent minus Congruent conditions for the main experiment). In these maps, significant ERD and ERS are represented with cool and warm colors, respectively, while green regions indicate non-significant clusters (i.e., $\mathrm{p}>$.05). It is worth noting here that, irrespective of the contrasts and frequency bands, significant effects revealed by the clusters-based permutation tests essentially indicated event-related desynchronization (ERD).

\section{Visual cortex}

For both the Congruent and Incongruent conditions there was no significant change in the power of gamma oscillations, over the occipital electrodes. However, as hypothesized in the Introduction, tracing with incongruent sensory feedback led to a decrease of alpha power over these electrodes relative to the Congruent condition. Tracing in this novel sensory context also led to a significant beta ERD over the right occipito-parietal electrodes. The impact of sensory incongruence on alpha and beta power is shown in Fig. 4 (second column of the first and second rows, respectively) where the clusters showing significant ERDs were largely circumscribed to the occipitoparietal region. The alpha and beta ERD can also be noted in Fig. 5 which shows the spectrograms averaged across all participants for a selective parieto-occipital electrode (i.e., POz) for both the Congruent and Incongruent conditions.

Source estimation revealed significant bilateral alpha and beta ERDs (although more pronounced over the right hemisphere) in the occipital and occipito-parietal (including the cuneus and precuneus) regions during the incongruence between visual and somatosensory inputs. This can be seen (except for the inner posterior regions) in Fig. 6 which displays the nonparametric statistical source maps of the alpha (upper panels), beta (middle panels), and gamma (lower panels) ERDs for both contrasts (i.e., Congruent minus Static conditions, Incongruent minus Congruent conditions).

\section{Sensorimotor cortex}

In accordance with previous results (see Introduction), tracing the shape in the Congruent condition elicited large alpha and beta ERDs in electrodes overlaying both sensorimotor cortices (Fig. 4). The statistical source maps confirmed the presence of significant movement-induced
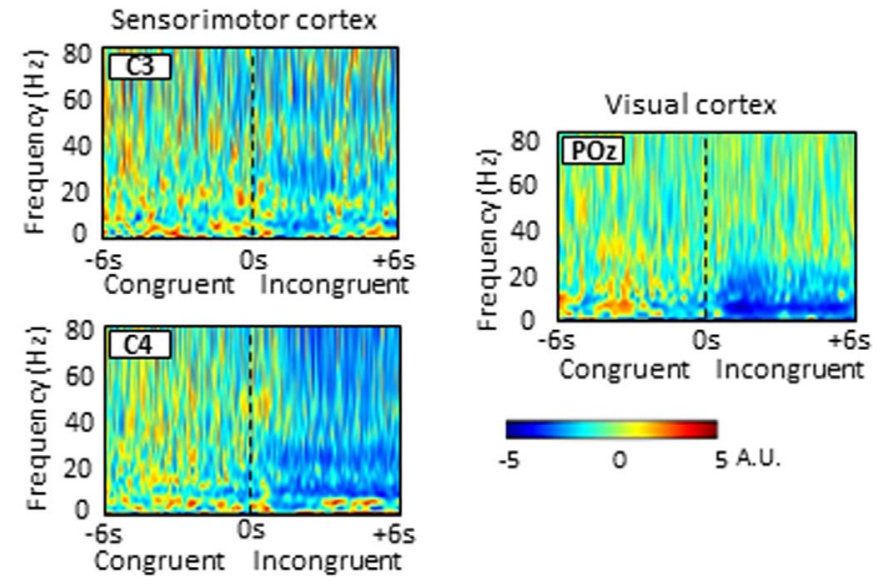

Fig. 5. Spectrograms averaged across all participants for selective electrodes overlying the left (C3) and right (C4) somatosensory cortices and the visual cortex (POz) for the Incongruent vs Congruent contrast (frequency range from $1 \mathrm{~Hz}$ to $80 \mathrm{~Hz}$ ). The vertical dashed lines represent the onsets of the incongruence between visual and somatosensory feedback.

(i.e., Congruent/Static contrast) alpha and beta ERDs over the bilateral sensorimotor cortices (Fig. 6).

However, the effect of the sensory incongruence on the power of beta and gamma was more complex than predicted. In contrast to the hypothesized beta ERS, the cluster-based permutation test revealed additional beta ERD over the sensorimotor cortices in the Incongruent condition (Figs. 4 and 5). Sources of this additional beta ERD included both sensorimotor cortices (Fig. 6). However, consistent with our hypothesis, we found a strong gamma ERD in the Incongruent condition. The statistical source maps of gamma revealed that, in the hemisphere contralateral to the drawing hand (i.e., left hemisphere), the gamma ERD occurred in the upper bank of the Sylvian fissure. This region is compatible with the human secondary somatosensory, parietal-ventral, and parietal-rostroventral areas.

\section{Other cortical regions}

Investigating gain modulation of visual and somatosensory inputs during the control of movement, the occipital and central regions represented the main targets of our analyses. However, it is worth noticing that significant beta and gamma ERDs also emerged in the Incongruent condition over regions that were not among the predefined regions of interest (see cluster-based permutation tests, Fig. 4). Such findings are to be expected given the widespread cortical network involved in the control of visuomotor tasks, particularly during response conflict (Fan et al., 2007). Source reconstructions indicated that large beta ERD was also present bilaterally in the motor and premotor cortices, and in the right posterior parietal and frontal cortices while bilateral gamma ERD also occurred in the frontal cortex (Fig. 6).

\section{Transitions between conditions}

Fig. 7 provides, for illustrative purposes, the temporal evolution of alpha power in the Congruent and Incongruent conditions, averaged across all participants in the source space, for both central and occipital vertices. The temporal course of alpha power can also be seen in Fig. 5 , which shows the spectrograms averaged across all participants in the Congruent and Incongruent conditions for central and occipital electrodes. The alpha band was chosen for this illustration because it showed significant ERDs over the somatosensory (left panel) and the visual (right panel) cortices, in the Congruent and Incongruent conditions, respectively. The time courses of alpha power were drawn from the vertices indicated by "X" in Fig. 7.

The trace time-locked to the movement onset shows that the alpha 


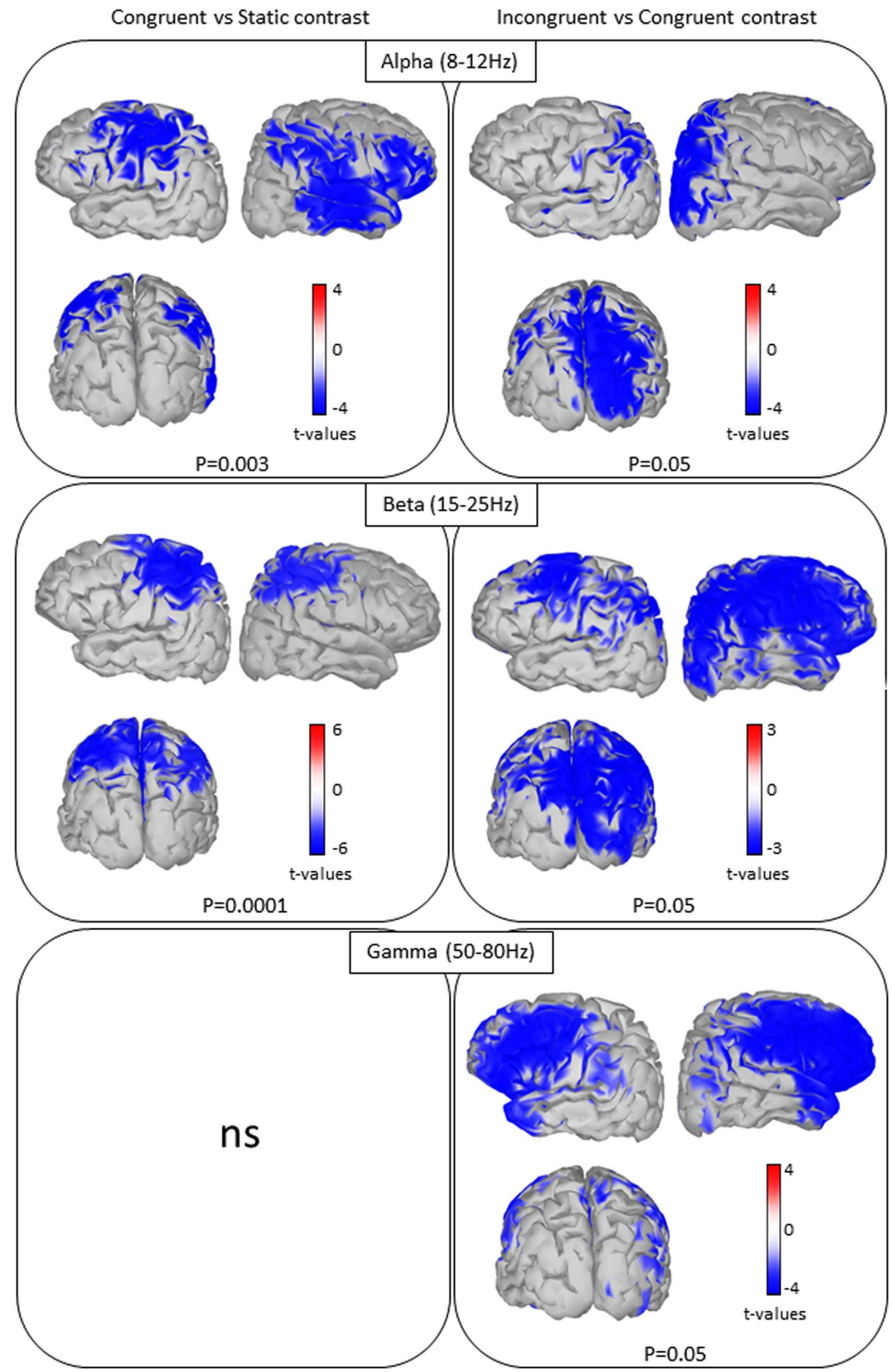

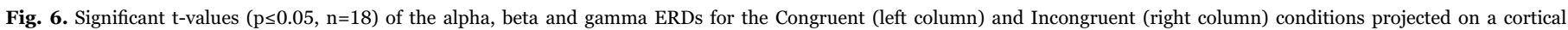

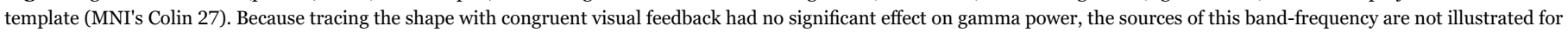

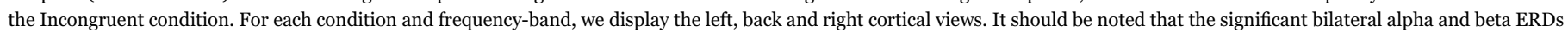
found in the cuneus and precuneus in the Incongruent condition are not shown. 
Congruent minus

Static contrast

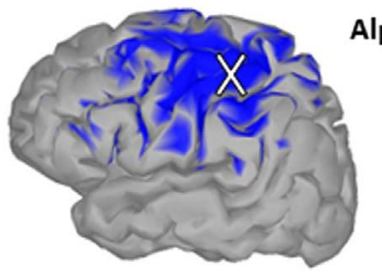

Alpha power

Incongruent minus

Congruent contrast
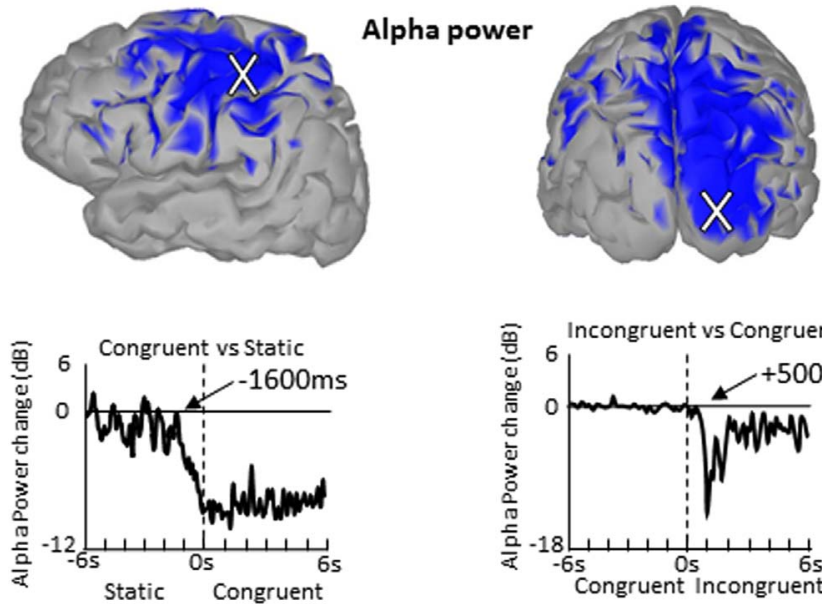

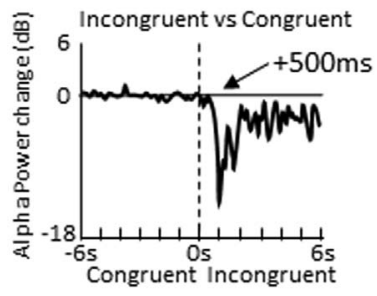

Fig. 7. Temporal evolution of the alpha $(8-12 \mathrm{~Hz})$ power in the source space, averaged across all participants. The dynamics of the alpha ERD is shown for the left somatosensory cortex for the Congruent minus Static contrast (time locked on the movement onset, left panel) and for the right visual cortex for the Incongruent minus Congruent contrast (time locked at the incongruence onset (right panel). White crosses on the cortical views represent the point where the alpha power has been extracted.

ERD observed in the somatosensory cortex started $\sim 1600 \mathrm{~ms}$ before participants started their tracings and reaching a relatively stable level $\sim 2 \mathrm{~s}$ later. The trace time-locked to the onset of the Incongruent condition shows that the alpha ERD observed in the visual cortex occurred $\sim 500 \mathrm{~ms}$ after the visual and somatosensory feedback of the pen position became incongruent. The power of alpha then decreased with a steep slope, reaching its minimal value $\sim 500 \mathrm{~ms}$ later. Then the alpha ERD decreased and reached a relatively stable level $\sim 1 \mathrm{~s}$ later.

\section{Correlations EEG-behavior}

As evidenced by the behavioral analyses (i.e., distance and radial error indices, average speed), movements produced in the Congruent and Incongruent conditions had different spatiotemporal characteristics (although very marginally for tracing speed). In the light of these results, we performed Spearman correlation analyses to determine whether the alpha, beta, and gamma ERDs observed in the Incongruent condition were linked with the observed behavioral changes. These correlation analyses were carried out with sets of electrodes that were part of the significant clusters in the statistical maps computed when participants traced the shapes with incongruent feedback (see Fig. 4): $\mathrm{C} 3$ and $\mathrm{C} 4$ which overlaid the somatosensory cortices (significant beta and gamma ERDs) and $\mathrm{POz}$ which overlaid the visual cortex (significant alpha ERDs). Importantly, none of the analyses revealed a significant correlation between frequency-band powers and tracing performance variables (all $\mathrm{p}>0.05$, all $\mathrm{R}$ ranged between 0.05 and 0.36 ). These results suggest that the observed difference of movement characteristics between the Congruent and Incongruent conditions had little effect on the computed frequency power.

\section{Ocular behavior}

EOG recordings were analyzed to determine whether the supplemental ERDs observed in the Incongruent condition might have resulted from different ocular behavior. Our analyses revealed very few occurrences of saccades and blinks during the trials (average per trial of 0.02 and 0.32 , respectively). The number of saccades ( $\mathrm{t}(17)$ $=1.77, \mathrm{p}=.09)$ and the number of blinks $(\mathrm{t}(17)=1.61, \mathrm{p}=.13)$ did not significantly differ between the Congruent and Incongruent conditions. The very small number of saccades confirms that participants complied with the requirement to gaze at the cursor of the pen during the entire duration of the trials.

\section{Control experiment}

The control experiment allowed testing whether the supplemental ERDs found in the Incongruent condition resulted from time-related effects rather than from the incongruence between visual and somatosensory inputs during the tracing movements. We compared the alpha, beta, and gamma power computed in the same two time windows as in the Congruent and Incongruent conditions of the main experiment (using the same cluster-based permutation tests) but when participants continuously traced the shape with congruent feedback (see Fig. 2). As illustrated in Fig. 4 (green maps of the last column), no significant power change (i.e., cluster) was observed for any frequency-band between the first and second time windows with congruent feedback. These findings provide strong evidence that the changes of power observed for all analyzed frequency-bands during the Incongruent condition in the main experiment did not result from time-related effects.

\section{Discussion}

This time-frequency investigation of the brain oscillatory activity identified possible neural processes contributing to the weighting of visual and somatosensory information during goal-directed hand movements. Using a protocol known to increase the need for sensory re-weighting, we found a large decrease of alpha and beta power over the occipital area when participants traced the contour of a shape with incongruent visual and somatosensory feedback. This decreased power in low and middle frequency bands is consistent with the hypothesized facilitation of visual processes when the participants controlled their movements with incongruent sensory feedback. Meanwhile, we found parallel beta and gamma desynchronizations in somatosensory cortex which, to the best of our knowledge, has never been reported in previous studies. The gamma ERD is in line with degraded binding processes and reduced integration of proprioceptive input for controlling movements with incongruent visual and somatosensory feedback. The parallel beta ERD could be specifically linked to somatosensory recalibration processes in order to adapt to the sensory incongruence.

\section{Visual cortex}

Consistent with our predictions, we found decreased alpha and beta power in the occipital region when participants traced the shape with incongruent sensory feedback. It is well recognized that alpha power is inversely correlated to cortical excitability (Anderson and Ding, 2011; Lange et al., 2013; Pfurtscheller and Lopes da Dilva, 1999; Romei et al., 2008), and that alpha and beta ERDs increase in tasks requiring a great deal of visuo-spatial attention (Mazaheri et al., 2014; Medendorp et al., 2007; Pavlidou et al., 2014; Pfurtscheller and Klimesch, 1990; Thut et al., 2006; Wyart and Tallon-Baudry, 2008). Thus, it is possible that the decreased power in these low and medium frequency-bands identified in the occipital region constituted the oscillatory correlates of increased visual feedback gain for tracing movements performed with incongruent sensory feedback. This increased gain, which was observed $\sim 500 \mathrm{~ms}$ after the onset of the sensory incongruence as suggested by the latency of the alpha ERD, could serve to prepare and promote visual information for the higher order processes involved in online movement control and sensorimotor adaptation. The observed occipital alpha ERD is therefore also consistent with prior studies showing that task difficulty amplifies the activity of neuronal populations within the visual cortex (Chen et al., 2008), notably when participants need to solve cognitive and sensory conflicts (Egner and Hirsch, 2005; Kerns et al., 2004). Moreover, because they were more pronounced over the right occipital lobe, the decrease of alpha and beta 
power could be more specifically related to spatial orientation processes when the participants were provided with biased visual feedback of their tracing movements (Orban et al., 1997; Schiltz et al., 1999).

With respect to the Static condition, movements performed with congruent visual and proprioceptive feedback neither decreased alpha power nor increased gamma power in the visual cortex. This result may appear to contradict the well documented EEG spectral content during visual processing (e.g., Ofori et al., 2015; Pfurtscheller et al., 2003; Tallon-Baudry, 2009). Most likely, this lack of modulation of alpha (i.e., decrease) and gamma (i.e., increase) oscillations during the visuallyguided movement could be explained by the large amount of visuallybased cognitive processes already engaged before the movement (i.e., in the Static condition). Specifically, during this pre-tracing condition, participants had to keep their gaze on the pen's cursor whilst awaiting for the visual cue that indicated both the time and the direction of the tracing movement. The fact that visual stimulation, and both temporal and spatial expectation all produce widespread alpha ERD and gamma ERS in the visual cortex (Fründ et al., 2008; Lima et al., 2011) may explain the absence of power change in these frequency bands when participants traced the shape with congruent visual and somatosensory feedback.

\section{Sensorimotor cortex}

Our results revealed decreased power of alpha- and beta-band oscillations in the sensorimotor cortices when participants traced the shape with congruent visual and somatosensory feedback. These power changes, which started $\sim 1600 \mathrm{~ms}$ before the imperative signal for alpha oscillations, are classically reported before and during movements (e.g., Chung et al., 2017; Heinrichs-Graham and Wilson, 2015; Pfurtscheller and Neuper, 1994; Zaepffel et al., 2013). These activities are interpreted as a transition from an inactive to active state of the cortex, and could be reflective of sensorimotor processing (Chen et al., 2003; Crone et al., 1998a; Pfurtscheller and Neuper, 1994).

As a key finding of the present study, we found that the power of beta and gamma oscillations both reduced during exposure to sensory incongruence. To the best of our knowledge, this is the first report of simultaneous beta and gamma ERDs in areas dedicated to sensorimotor processes. This novel and unexpected finding raises questions as to the specificity of beta and gamma ERDs whose basic functions have been closely associated to increased (beta ERD) and decreased (gamma ERD) processing of somatosensory inputs (Cheyne et al., 2008; Crone et al., 1998a, 1998b; Szurhaj et al., 2005). We believe that elements of a response to these questions might be found by considering more specifically the processes underlying visuomotor adaptation, sensory binding, and control of movements with incongruent sensory feedback.

For instance, it has been suggested that adaptation to a new visuomotor environment results from re-alignment between visual and proprioceptive frames of reference and involves somatosensory recalibration (Cressman and Henriques, 2015; O'Shea et al., 2014; Redding et al., 2005). These operations most likely require the processing of somatosensory feedback. According to this hypothesis, beta ERD would be associated to this sensorimotor adaptation when producing motor actions with incongruent visual and somatosensory feedback. This suggestion is consistent with a recent observation made by Torrecillos et al. (2015). These authors found beta ERD during the preparation of a force-field adapted reaching movement, if the movement was preceded by a movement in the same force field (see also Thoroughman and Shadmehr, 2000). Importantly, the use of movements with short duration in Torrecillos et al., (2015) study (i.e., $\sim 650 \mathrm{~ms}$ ) may have favored the sensory remapping processes during movement planning rather than during movement execution. In the present experiment, participants were successively exposed to long periods with normal and incongruent feedback of similar durations (i.e., $\sim 8 \mathrm{~s}$ ). This procedure is likely to be conducive to adaptive processes specifically during the sensory incongruence time windows, where beta power further decreased. These processes may have contributed to the improved quality of the tracing performance showed by the participants with repetitive exposure to the sensory incongruence.

In addition, the beta ERD evidenced with sensory incongruence could have been related to movement selection processes, i.e. to an increased difficulty to select the appropriate movement to follow the outline of the shape. This is suggested by a recent study of Brinkman et al. (2014) showing that the power of beta band decreases in the sensorimotor cortex when movement selection demands increase. In their study, movement selection demands were manipulated by presenting objects whose orientations evoked either stereotyped or different grasping movements. In the present Incongruent condition, the importance of movement selection processes was most likely augmented when participants produced movements that failed to keep the pen's cursor on the outline of the shape.

As for the decreased power of gamma that paralleled the beta ERD in the somatosensory region, it could have been linked to processes involved in multisensory binding and in the control of movement during sensory incongruence. The sensory binding hypothesis is supported by studies showing that gamma power increases within the sensory cortices when a coherent percept emerges from different sensory inputs; but, decreases with the presentation of incongruent sensory inputs (Ghazanfar et al., 2008; Krebber et al., 2015; Lutzenberger et al., 1995; Maier et al., 2008; Muller et al., 1996, 1997). Based on these findings, gamma activity was proposed as a neural marker for multimodal sensory integration, connecting neural assemblies that encode stimuli of different sensory modalities (Engel et al., 2012; Fries, 2009; Wang, 2010). In this light, the gamma ERD observed with incongruent sensory feedback may represent local functional EEG signatures of reduced feature-binding processes involving somatosensory input.

The decreased power of gamma might have reduced the weight of somatosensory input for controlling movements with discrepant visual and somatosensory information. The fact that the gamma ERD was observed in the upper bank of the Sylvian fissure contralateral to the drawing hand gives credit to this hypothesis. This region has been defined by human neuroimaging studies as being part of the secondary somatosensory cortex, and the parietal-ventral and parietal-rostroventral areas (Eickhoff et al., 2010; Hinkley et al., 2007; Ruben et al., 2001). Most importantly, this cortical region is thought to be specifically involved in the integration of proprioceptive input for motor control (Eickhoff et al., 2010; Hinkley et al., 2007). It is also densely connected with the posterior parietal cortex (Disbrow et al., 2003), a key region for controlling movements through somatosensory inputs (Andersen and Buneo, 2002; Desmurget et al., 1999; Reichenbach et al., 2014). Therefore the gamma ERD might have played an important role in reducing the contribution of somatosensory inputs for controlling hand movements in the novel visuomotor environment. It is worth noting that because of arm (Arnfred et al., 2007) and extraocular (Yuval-Greenberg et al., 2008) muscular activities are associated with increased synchronization in the gamma-band, the gamma ERD observed in the sensorimotor cortex in the Incongruent condition did not result from an increased muscular activity.

\section{Changes of neural oscillations in other cortical regions}

Significant beta and gamma ERDs also emerged in the Incongruent condition over the posterior parietal (PPC) and frontal areas, which are outside our pre-defined regions of interest. Source analyses revealed that beta ERDs were more pronounced in the right hemisphere (see Fig. 6). Beta activity in the right PPC has been poorly studied with regard to motor control (either with or without sensory incongruence). However, the right PPC is clearly identified as being crucial for learning new visuomotor transformations (Balslev et al., 2005; Clower et al., 
1996; Coombes et al., 2010; Krakauer et al., 2004); for processing visuo-spatial information (Blankenburg et al., 2010; Corbetta et al., 2000; Marshall and Fink, 2001); and for processing information related to the hand (Fink et al., 1999). The beta ERD evidenced in the right PPC might have contributed to enabling these processes, which appeared critical in the present study for continuing to trace the shape despite incongruent hand visual and somatosensory feedback and for adapting to the new visuomotor environment.

The right PPC is also implicated in processing spatial aspects of complex motor actions (Weiss et al., 2006). Most importantly, such spatio-motor related processing was found to be associated with a decreased power of beta oscillation in the right PPC (HeinrichsGraham and Wilson, 2015; Tzagarakis et al., 2010). In accordance with these previous studies, the present findings confer important, and yet insufficiently explored, functions to PPC beta oscillations for controlling movements with discrepant sensory information. Further studies are required to deepen knowledge on these functions.

On the other hand, beta and gamma ERDs revealed in the right frontal cortex might be related to cognitive functions when controlling movements with spatially-incongruent sensory inputs. This is supported by the results of a recent study by Rosen and Reiner (2016) showing decreased power in these medium and high frequency-bands in the right prefrontal cortex when participants were cognitively engaged in a spatial problem-solving task. Note that the authors did not observe these ERDs when the solution to the spatial problem was found by insight (i.e., non-continuous processes, see also Sheth et al., 2009). Our finding that tracing performance was still degraded by the sensory incongruence at the end of the experimental session argues in favor of continuous processes to solve the spatial problem and is therefore consistent with the observed beta and gamma ERDs in the right frontal cortex. The gamma ERD revealed in the left frontal region could have, in turn, contributed to inhibit motor actions that are normally appropriate in the context of non-biased visual feedback (Iijima et al., 2015).

Source analyses of the beta oscillations also showed greater desynchronization in the motor and premotor areas when the participants traced the shapes with incongruent visual and somatosensory feedback. A greater beta ERD in the motor cortex has also been evidenced by Chung et al. (2017) when the visual feedback gain of arm displacement (provided through a computer monitor) was increased during goal-directed movement as compared to a condition without increased visual feedback gain. When visual feedback of the movement was increased, the authors also observed greater beta-band connectivity from medial posterior parietal (i.e., precuneus) to motor cortices during the correction phase of the movements. Chung et al. (2017) suggested that during the sustained beta-band desynchronization, the motor cortex may be receiving input from the medial posterior parietal cortex. This area, which showed significant alpha ERD in the present Incongruent condition, is an important cortical area for the visual control of movements (Karnath and Pérenin, 2005). In the current study, such processes might have contributed to increase the weight of visual input for controlling movements in the sensory incongruent condition. Finally, the supplemental beta ERD revealed in the premotor regions could have favored the selection of the motor responses based on visual spatial cues (Chouinard and Paus, 2006; Wise, 1985).

\section{Possible impact of ocular movements}

Our behavioral analyses revealed that the tracing speed was slightly greater in the Incongruent condition than in the Congruent condition $(2.6 \mathrm{~mm} / \mathrm{s}$ vs $2.3 \mathrm{~mm} / \mathrm{s})$. Because participants were required to keep their gaze on the cursor while tracing the contour of the shape, the retinal slip resulting from the slow pursuit eye movement presumably differed between both conditions. However, due to very small tracing speed difference (i.e., $<1 \mathrm{~mm} / \mathrm{s}$; Cohen's d of only 0.32) it seems reasonable to assume that this difference was too small to be detected with EEG recordings.

On the other hand, smooth pursuit eye movement is associated with increased gamma power in frontal eye field (FEF), in the ventral intraparietal sulcus (VIPS) and in occipital areas (Bastin et al., 2012). Lee and Lisberger (2013) have also recently reported that spike-field coherence in the gamma band predicts middle temporal area (MT)smooth pursuit direction correlations. In this light, it is likely that the activity related to the slow smooth pursuit eye movement had little or no effect on the gamma ERD that we found in the somatosensory cortex, which was one of two regions of interest in the present study.

In sum, the supplemental ERDs observed in the Incongruent condition unlikely resulted from different ocular behavior between the Congruent and Incongruent conditions.

\section{Conclusion}

We found that the control of hand movement under discrepant visual and somatosensory inputs is associated with decreased alpha$(8-12 \mathrm{~Hz})$ and beta- $(15-25 \mathrm{~Hz})$ band neural oscillations in the visual cortex and decreased beta and gamma-band frequencies $(30-50 \mathrm{~Hz})$ in the sensorimotor cortex. We conclude that these power modulations of low, medium, and high frequency-bands contributed to distinct processes linked to the online control of movement and sensorimotor adaptation when faced with incongruent sensory stimuli. Taken together, our findings are therefore in line with the existence of a general sensory gain control mechanism driven by the adaptive state of the sensorimotor system in a given sensory context. The control exerted over the visual and somatosensory inputs may originate from different neural substrates, such as the thalamus (Purushothaman et al., 2012; Womelsdorf et al., 2014), the prefrontal cortex (Barcelo et al., 2000; Gregoriou et al., 2014; Haggard and Whitford, 2004) and the cerebellum (Cebolla et al., 2017; Knight et al., 1999).

\section{Conflict of Interest}

The authors declare that the research was conducted in the absence of any commercial or financial relationships that could be construed as a potential conflict of interest.

\section{Acknowledgements}

We would like to thank Gerome Manson, Sylvain Madec, Romain Chaumillon and Daniele Schön for useful advice, reading, and comments.

\section{References}

Andersen, R.A., Buneo, C.A., 2002. Intentional maps in posterior parietal cortex. Annu. Rev. Neurosci. 25, 189-220.

Anderson, K.L., Ding, M., 2011. Attentional modulation of the somatosensory Mu rhythm. J. Neurosci. 180, 165-180.

Arnfred, S.M., Hansen, L.K., Parnas, F., Mørup, M., 2007. Proprioceptive evoked gamma oscillations. Brain Res. 1147, 167-174.

Balslev, D., Christensen, L.O.D., Lee, J.H., Law, I., Paulson, O.B., Miall, R.C., 2004 Enhanced accuracy in novel mirror drawing after repetitive transcranial magnetic stimulation-induced proprioceptive deafferentation. J. Neurosci. 24, 9698-9702.

Barcelo, F., Suwazono, S., Knight, R.T., 2000. Prefrontal modulation of visual processing in humans. Nat. Neurosci. 3, 399-403.

Bastin, J., Lebranchu, P., Jerbi, K., Kahane, P., Orban, G., Lachaux, J.-P., Berthoz, A., 2012. Direct recordings in human cortex reveal the dynamics of gamma-band [50$150 \mathrm{~Hz}]$ activity during pursuit eye movement control. Neuroimage 63, 339-347.

Bauer, M., Oostenveld, R., Peeters, M., Fries, P., 2006. Tactile spatial attention enhances gamma-band activity in somatosensory cortex and reduces low-frequency activity in parieto-occipital areas. J. Neurosci. 26, 490-501.

Bernier, P.M., Burle, B., Vidal, F., Hasbroucq, T., Blouin, J., 2009. Direct evidence for cortical suppression of somatosensory afferents during visuomotor adaptation. Cereb. Cortex 19, 2106-2113.

Blankenburg, F., Ruff, C.C., Bestmann, S., Bjoertomt, O., Josephs, O., Deichmann, R., Driver, J., 2010. Studying the role of human parietal cortex in visuospatial attention with concurrent TMS-fMRI. Cereb. Cortex 20, 2702-2711.

Brainard, D.H., 1997. The psychophysics toolbox. Spat. Vis. 10, 433-436. 
Brinkman, L., Stolk, A., Dijkerman, C., Lange, F.P., Toni, I., 2014. Distinct roles for alpha and beta band oscillations during mental stimulation of goal directed actions. J. Neurosci. 34, 14783-14792.

Cazelles, B., Chavez, M., Berteaux, D., Ménard, F., Vik, J.O., Jenouvrier, S., Stenseth, N.C., 2008. Wavelet analysis of ecological time series. Oecologia 156, 287-304.

Cebolla, A.M., Petieau, M., Dan, B., Balazs, L., McIntyre, J., Chéron, G., 2016. Cerebellar contribution to visuoattentional alpha rhythm: insights from weightlessness. Sci Rep. 6, 37824.

Chung, J.W., Ofori, E., Misra, G., Hess, C.W., Vaillancourt, D.E., 2017. Beta-band activity and connectivity in sensorimotor and parietal cortex are important for accurate motor performance. Neuroimage 144, 164-173.

Chen, Y., Ding, M., Kelso, S.J.A., 2003. Task-related power and coherence changes in neuromagnetic activity during visuomotor coordination. Exp. Brain Res. 148, $105-116$.

Chen, Y., Martinez-Conde, S., Macknik, S.L., Bereshpolova, Y., Swadlow, H.A., Alonso, J.M., 2008. Task difficulty modulates the activity of specific neuronal populations in primary visual cortex. Nat. Neurosci. 11, 974-982.

Cheyne, D., Bells, S., Ferrari, P., Gaetz, W., Bostan, A.C., 2008. Self-paced movements induce high-frequency gamma oscillations in primary motor cortex. Neuroimage 42, $332-342$.

Cheyne, D., Gaetz, W., Garnero, L., Lachaux, J.P., Ducorps, A., Schwartz, D., Varela, F.J., 2003. Neuromagnetic imaging of cortical oscillations accompanying tactile stimulation. Cogn. Brain Res. 17, 599-611.

Chouinard, P.A., Paus, T., 2006. The primary motor and premotor areas of the human cerebral cortex. Neuroscientist 12, 143-152.

Clower, D.M., Hoffman, J.M., Votaw, J.R., Faber, T.L., Woods, R.P., Alexander, G.E., 1996. Role of posterior parietal cortex in the recalibration of visually guided reaching. Nature 383, 618-621.

Cohen, J., 1988. Statistical Power Analysis for the Behavioral Sciences 2 edition. Routledge, Hillsdale. N.J..

Cohen, M.X., 2014. Analyzing Neural Time Series Data. Theory and Practice. MIT Press, Cambridge. MA.

Coombes, S.A., Corcos, D.M., Sprute, L., Vaillancourt, D.E., 2010. Selective regions of the visuomotor system change with force error. J. Neurophysiol. 103, 2114-2123.

Corbetta, M., Kincade, J.M., Ollinger, J.M., McAvoy, M.P., Shulman, G.L., 2000. Voluntary orienting is dissociated from target detection in human posterior parietal cortex. Nat. Neurosci. 3, 292-297.

Cressman, E.K., Henriques, D.Y.P., 2015. Generalization of reach adaptation and proprioceptive recalibration at different distances in the workspace. Exp. Brain Res. 233, 817-827.

Crone, N.E., Miglioretti, D.L., Gordon, B., Sieracki, J.M., Wilson, M.T., Uematsu, S., Lesser, R.P., 1998a. Functional mapping of human sensorimotor cortex with electrocorticographic spectral analysis. I. Alpha and beta event-related desynchronization. Brain 121, 2271-2299.

Crone, N.E., Miglioretti, D.L., Gordon, B., Lesser, R.P., 1998b. Functional mapping of human sensorimotor cortex with electrocorticographic spectral analysis. II. Eventrelated synchronization in the gamma band. Brain 121, 2301-2315.

Delorme, A., Makeig, S., 2004. EEGLAB: an open source toolbox for analysis of singletrial EEG dynamics including independent component analysis. J. Neurosci. Methods 15, 9-21.

Desmurget, M., Epstein, C.M., Turner, R.S., Prablanc, C., Alexander, G.E., Grafton, S.T., 1999. Role of the posterior parietal cortex in updating reaching movements to a visual target. Nat. Neurosci. 2, 563-567.

Disbrow, E., Litinas, E., Recanzone, G.H., Padberg, J., Krubitzer, L., 2003. Cortical connections of the second somatosensory area and the parietal ventral area in macaque monkeys. J. Comp. Neurol. 462, 382-399.

Eickhoff, S.B., Jbabdi, S., Caspers, S., Laird, A.R., Fox, P.T., Zilles, K., Behrens, T.E.J., 2010. Anatomical and functional connectivity of cytoarchitectonic areas within the human parietal operculum. J. Neurosci. 30, 6409-6421.

Engel, A.K., Senkowski, D., Schneider, T.R., 2012. Multisensory integration through neural coherence. In: Simon, S.A., Nicolelis, M.A.L. (Eds.), The neural bases of multisensory processes. CRC press, Boca Raton, 115-130.

Ergenoglu, T., Demiralp, T., Bayraktaroglu, Z., Ergen, M., Beydagi, H., Uresin, Y., 2004. Alpha rhythm of the EEG modulates visual detection performance in humans. Cogn. Brain Res. 20, 37-383.

Egner, T., Hirsch, J., 2005. Cognitive control mechanisms resolve conflict through cortical amplification of task-relevant information. Nat. Neurosci. 8, 1784-1790.

Ernst, M.O., Banks, M.S., 2002. Human integrate visual and haptic information in statistically optimal fashion. Nature 415, 429-433.

Fan, F., Kolster, R., Ghajar, J., Suh, M., Knight, R.T., Sarkar, R., McCandliss, B.D., 2007. Response anticipation and response conflict: an event-related potential and functional magnetic resonance imaging study. J. Neurosci. 27, 2272-2282.

Fink, G.R., Marshall, J.C., Halligan, P.W., Frith, C.D., Driver, J., Frackowiak, S.J., Dolan, R.J., 1999. The neural consequence of conflict between intention and the senses. Brain 122, 497-512.

Fitzgibbon, S.P., Lewis, T.W., Powers, D.M.W., Whitham, E.W., Willoughby, J.O., Pope, K.J., 2013. Surface Laplacian of central scalp electrical signals is insensitive to muscle contamination. IEEE Trans. Biomed. Eng. 60, 4-9.

Fries, P., 2009. Neural gamma-band synchronization as a fundamental process in cortical computation. Ann. Rev. Neurosci. 32, 209-224.

Fründ, I., Schadow, J., Busch, N.A., Naue, N., Körner, U., Herrmann, C.S., 2008. Anticipation of natural stimuli modulates EEG dynamics: physiology and simulation. Cogn. Neurodyn. 2, 89-100.

Gagné-Lemieux, L., Simoneau, M., Tessier, J.F., Billot, M., Blouin, J., Teasdale, N., 2014. Balance control interferes with the tracing performance of a pattern with mirrorreversed vision in older persons. Age 36, 823-837.
Ghazanfar, A.A., Chandrasekaran, C., Logothetis, N.K., 2008. Interactions between the superior temporal sulcus and auditory cortex mediate dynamic face/voice integration in rhesus monkeys. J. Neurosci. 28, 4457-4469.

Gray, C.,M., Di Prisco, G.V., 1997. Stimulus-dependent neuronal oscillations and local synchronization in striate cortex of the alert cat. J. Neurosci. 17, 3239-3253.

Gregoriou, G.G., Rossi, A.F., Ungerleider, L.G., Desmione, R., 2014. Lesion of prefrontal cortex reduce attentional modulation of neuronal responses and synchrony in V4. Nat. Neurosci. 17, 1003-1011.

Haggard, P., Whitford, B., 2004. Supplementary motor area provides an efferent signal for sensory suppression. Cogn. Brain Res. 19, 52-58.

Haegens, S., Händel, B.F., Jensen, O., 2011. Top-down controlled alpha band activity in somatosensory areas determines behavioral performance in a discrimination task. J. Neurosci. 31, 5197-5204.

Hämäläinen, M., 2009. MNE software User's Guide. Massachusetts General Hospital, Charlestown (MA).

Hanslmayr, S., Aslan, A., Staudigl, T., Klimesch, W., Herrmann, C.S., Bäuml, K.H., 2007 Prestimulus oscillations predict visual perception performance between and within subjects. Neuroimage 37, 1465-1473.

Heinrichs-Graham, E., Wilson, T.W., 2015. Coding complexity in the human motor circuit. Hum. Brain Mapp. 36, 5155-5167.

Hinkley, L.B., Krubitzer, L.A., Nagarajan, S.S., Disbrow, E.A., 2007. Sensorimotor integration in S2, PV, and parietal rostroventral areas of the human sylvian fissure. J. Neurophysiol. 97, 1288-1297.

Iijima, M., Mase, R., Osawa, M., Shimizu, S., Uchiyama, S., 2015. Event-related synchronization and desynchronization of high-frequency electroencephalographic activity during a visual go/no-go paradigm. Neuropsychobiology 71, 17-24.

Karnath, H.O., Pérenin, M.T., 2005. Cortical control of visually guided reaching: evidence from patients with optic ataxia. Cereb. Cortex 15, 1561-1569.

Kerns, J.G., Cohen, J.D., MacDonald, A.W., Cho, R.Y., Stenger, V.A., Carter, C.S., 2004. Anterior cingulate conflict monitoring and adjustments in control. Science 303 1023-1026.

Knight, R.T., Staines, W.R., Swick, D., Chao, L.L., 1999. Prefrontal cortex regulates inhibition and excitation in distributed neural networks. Acta Psychol. 101, 159-178.

Koessler, L., Maillard, L., Benhadid, A., Vignal, J.P., Felblinger, J., Vespignani, H., Braun, M., 2009. Automated cortical projection of EEG sensors: anatomical correlation via the international 10-10 system. Neuroimage 46, 64-72.

Krakauer, J.W., Ghilardi, M.F., Mentis, M., Barnes, A., Veytsman, M., Eidelberg, D., Ghez, C., 2004. Differential cortical and subcortical activations in learning rotations and gains for reaching: a pet study. J. Neurophysiol. 91, 924-933.

Krebber, M., Harwood, J., Spitzez, B., Keil, J., Senkowski, D., 2015. Visuotactile motion congruence enhances gamma-bad activity in visual and somatosensory cortices. Neuroimage 117, 160-169.

Lajoie, Y., Paillard, J., Teasdale, N., Bard, C., Fleury, M., Forget, R., Lamarre, Y., 1992. Mirror drawing in a deaffernted patient and normal subjects, visuoproprioceptive conflict. Neurology 42, 1104-1106.

Lange, J., Oostenveld, R., Fries, P., 2013. Reduced occipital alpha power indexes enhanced excitability rather than improved visual perception. J. Neurosci. 33, 3212-3220.

Law, S.K., Rohrbaugh, J.W., Adams, C.M., Eckardt, M.J., 1993. Improving spatial and temporal resolution in evoked EEG response using surface Laplacians. Electroencephalogr. Clin. Neurophysiol. 88, 309-322.

Lebar, N., Bernier, P.-M., Guillaume, A., Mouchnino, L., Blouin, J., 2015. Neural correlates for task-relevant facilitation of visual input during visually-guided movements. Neuroimage 121, 39-50.

Lee, J., Lisberger, S.G., 2013. Gamma synchrony predicts neuron-neuron correlations and correlations with motor behavior in extrastriate visual area MT. J. Neurosci. 3, 19677-19688.

Lima, B., Singer, W., Neuenschwander, S., 2011. Gamma responses correlates with temporal expectation in monkey primary visual cortex. J. Neurosci. 31, $15919-15931$.

Lutzenberger, W., Pulvermüller, F., Elbert, T., Birbaumer, N., 1995. Visual stimulation alters local 40-Hz responses in humans: an EEG study. Neurosci. Lett. 183, 39-42.

Maier, J.X., Chandrasekaran, C., Ghazanfar, A.A., 2008. Integration of bimodal looming signals thrugh neuronal coherence in the temporal lobe. Curr. Biol. 18, 963-968.

Maris, E., Oostenveld, R., 2007. Nonparametric statistical testing of EEG and MEG data. J. Neurosci. Methods 164, 177-190.

Maris, E., 2012. Statistical testing in electrophysiological studies. Psychophysiology 49, $549-565$.

Marshall, J.C., Fink, G.R., 2001. Spatial cognition: where we were and were we are. Neuroimage 14, S2-S7, 765.

Mazaheri, A., Van Schouwenburg, M.R., Dimitrijevic, A., Denys, D., Cools, R., Jensen, O., 2014. Region-specific modulations in oscillatory alpha activity serve to facilitate processing in the visual and auditory modalities. Neuroimage 87, 356-362.

Medendorp, W.P., Kramer, G.F.I., Jensen, O., Oostenveld, R., Schoffelen, J.M., Fries, P., 2007. Oscillatory activity in human parietal and occipital cortex shows hemispheric lateralization and memory effects in a delayed double-step saccade task. Cereb. Cortex 17, 2364-2374.

Muller, M.M., Bosch, J., Elbert, T., Kreiter, A., Sosa, M.V., Sosa, P.V., Rochstroh, B., 1996. Visually induced gamma-band responses in human electroencephalographic activity, a link to animal studies. Exp. Brain Res. 112, 96-102.

Muller, M.M., Junghöfer, M., Elbert, T., Rochstroh, B., 1997. Visually induced gammaband responses to coherent and incoherent motion, a replication study. NeuroReport 8, 2575-2579.

Nunez, P.L., 2000. Toward a quantitative description of large-scale neocortical dynamic function and EEG. Behav. Brain Sci. 23, 371-398. 
Nunez, P.L., Srinivassan, R., 2006. Electric Fields of the Brain: the Neurophysics of EEG.. Oxford University Press, New York. NY.

Ofori, E., Coombes, S.A., Vaillancourt, D.E., 2015. 3D cortical electrophysiology of ballistic upper limb movement in humans. Neuroimage 115, 30-41.

Oostenveld, R., Fries, P., Maris, E., Schoffelen, J.M., 2011. FieldTrip, open source software for advanced analysis of MEG, EEG, and invasive electrophysiological data. Comput. Intell. Neurosci. 2011, 1-9.

Orban, G.A., Dupont, P., Vogels, R., Bormans, G., Mortelmans, L., 1997. Human brain activity related to orientation discrimination tasks. Eur. J. Neurosci. 9, 246-259.

O’Shea, J., Gaveau, V., Kandel, M., Koga, K., Susami, K., Prablanc, C., Rossetti, Y., 2014. Kinematic markers dissociate error correction from sensorimotor realignment during prism adaptation. Neuropsychologia 55, 15-24.

Pavlidou, A., Schnitzler, A., Lange, J., 2014. Distinct spatio-temporal profiles of betaoscillations within visual and sensorimotor areas during action recognition as revealed by MEG. Cortex 54, 106-116.

Pelli, D.G., 1997. The Video Toolbox software for visual psychophysics, transforming numbers into movies. Spat. Vis. 10, 437-442.

Perrin, F., Pernier, J., Bertrand, O., Echallier, J.F., 1989. Spherical splines for scalp potential and current density mapping. Electroencephalogr. Clin. Neurophysiol. 72, $184-187$.

Pfurtscheller, G., Graimann, B., Huggins, J.E., Levine, S.P., Schuh, L.A., 2003. Spatiotemporal patterns of beta desynchronization and gamma synchronization in corticographic data during self-paced movement. Clin. Neurophysiol. 114, 1226-1236.

Pfurtscheller, G., Klimesch, W., 1990. Topographical display and interpretation of eventrelated desynchronization during a visual-verbal task. Brain Topogr. 3, 85-93.

Pfurtscheller, G., Lopes da Silva, F.H., 1999. Event-related EEG/MEG synchronization and desynchronization: basic principles. Clin. Neurophysiol. 110, 1842-1857.

Pfurtscheller, G., Neuper, C., 1994. Event-related synchronization of mu rhythm in the EEG over the cortical hand area in man. Neurosci. Lett. 174, (96-96).

Pogosyan, A., Gaynor, L.D., Eusebio, A., Brown, P., 2009. Boosting cortical activity at beta-band frequencies slows movement in humans. Curr. Biol. 19, 1637-1641.

Purushothaman, G., Marion, R., Li, K., Casagrande, V.A., 2012. Gating and control of primary visual cortex by pulvinar. Nat. Neurosci. 15, 905-912.

Redding, G.M., Rossetti, Y., Wallace, B., 2005. Application of prism adaptation, a tutorial in theory and method. Neurosci. Biobehav. Rev. 29, 431-444.

Reichenbach, A., Thielscher, A., Peer, A., Bülthoff, H.H., Bresciani, J.-P., 2014. A key region in the human parietal cortex for processing proprioceptive hand feedback during reaching movements. Neuroimage 84, 615-625.

Romei, V., Brodbeck, V., Michel, C., Amedi, A., Pascual-Leone, A., Thut, G., 2008. Spontaneous fluctuations in posterior $a$-band EEG activity reflect variability in excitability of human visual areas. Cereb. Cortex 18, 2010-2018.

Romei, V., Gross, J., Thut, G., 2010. On the role of prestimulus alpha rhythms over occipito-parietal areas in visual input regulation, correlation or causation? J. Neurosci. 30, 8692-8697.

Rosen, A., Reiner, M., 2016. Right frontal gamma and beta band enhancement while solving a spatial puzzle with insight. Int. J. Psychophysiol.. http://dx.doi.org/ 10.1016/j.ijpsycho.2016.09.008.

Rossetti, Y., Desmurget, M., Prablanc, C., 1995. Vectorial coding of movement, vision, proprioception or both? J. Neurophysiol. 74, 457-463.

Ruben, J., Schweimann, J., Deuchert, M., Meyer, R., Krause, T., Curio, G., Villringer, K., Kurth, R., Villringer, A., 2001. Somatotopic organisation of human secondary somatosensory cortex. Cereb. Cortex 11, 463-473.

Sarlegna, F.R., Gauthier, G.M., Blouin, J., 2007. Influence of feedback modality on sensorimotor adaptation, contribution of visual, kinesthetic, and verbal cues. J. Mot. Behav. 39, 247-258.

Sarlegna, F.R., Sainburg, R.L., 2007. The effect of target modality on visual and proprioceptive contributions to the control of movement distance. Exp. Brain Res. $176,267-280$.

Schiltz, C., Bodart, J.M., Dubois, S., Dejardin, S., Michel, C., Roucoux, A., Crommelinck, M., Orban, G.A., 1999. Neuronal mechanisms of perceptual learning: changes in human brain activity with training in orientation discrimination. Neuroimage 9, 46-62.

Scott, S.H., 2004. Optimal feedback control and the neural basis of volitional motor control. Nature 5, 534-546.

Sheth, B.R., Sandkühler, S., Bhattacharya, J., 2009. Posterior beta and anterior gamma oscillations predict cognitive insight. J. Cogn. Neurosci. 21, 1269-1279.

Sober, S.J., Sabes, P.N., 2003. Multisensory integration during motor planning. J.
Neurosci. 23, 6982-6992.

Szurhaj, W., Bourriez, J.L., Kahane, P., Chauvel, P., Mauguière, F., Derambure, P., 2005. Intracerebral study of gamma rhythm reactivity in the sensorimotor cortex. Eur. J. Neurosci. 24, 1223-1235.

Tadel, F., Baillet, S., Mosher, J.C., Pantazis, D., Leahy, R.M., 2011. Brainstorm, a userfriendly application for MEG-EEG analysis. Comput. Intell. Neurosci.. http:// dx.doi.org/10.1155/2011/879716.

Tallon-Baudry, C., Bertrand, O., Delpuech, C., Pernier, J., 1996. Stimulus specificity of phase-locked and non-phase-locked $40 \mathrm{~Hz}$ visual responses in human. J. Neurosci. $16,4240-4249$.

Tallon-Baudry, C., Bertrand, O., 1999. Oscillatory gamma activity in human and its role in object representation. Trends Cogn. Sci. 3, 151-162.

Tallon-Baudry, C., 2009. The roles of gamma-bands oscillatory synchrony in human visual congnition. Front. Biosci. 14, 321-332.

Thoroughman, K.A., Shadmehr, R., 2000. Learning of action through adaptive combination of motor primitives. Nature 407, 742-747.

Thürer, B., Stockinger, C., Focke, A., Putze, F., Schultz, T., Stein, T., 2016. Increased gammaband power duringmovement planning coincides with motor memory retrieval. NeuroImage 125, 172-181.

Thut, G., Nietzel, A., Brandt, S.A., Pascual-Leone, A., 2006. a-band electroencephalographic activity over occipital cortex indexes visuospatial attention bias and predicts visual target detection. J. Neurosci. 26, 9494-9502.

Todorov, E., Jordan, M.I., 2002. Optimal feedback control as a theory of motor coordination. Nature 5, 1226-1235.

Torrecillos, F., Alayrangues, J., Kilavik, B.E., Malfait, N., 2015. Distinct modulations in sensorimotor postmovement and foreperiod $\beta$-band activities related to error salience processing and sensorimotor adaptation. J. Neurosci. 35, 12753-12765.

Torrence, C., Compo, G.P., 1998. A practical guide to wavelet analysis. Bull. Am. Meteorol. Soc. 79, 61-78.

Tzagarakis, C., Ince, N.F., Leuthold, A.C., Pellizzer, G., 2010. Beta-band activity during motor planning reflects response uncertainty. J. Neurosci. 34, 11270-11277.

van Dijk, H., Schoffelen, J.M., Oostenveld, R., Jensen, O., 2008. Prestimulus oscillatory activity in the alpha band predicts visual discrimination ability. J. Neurosci. 28, 1816-1823.

van Ede, F., de Lange, F., Jensen, O., Maris, E., 2011. Orienting attention to an upcoming tactile event involves a spatially and temporally specific modulation of sensorimotor alpha- and beta-band oscillations. J. Neurosci. 31, 2016-2024.

van Ede, F., Köster, M., Maris, E., 2012. Beyond establishing involvement, quantifying the contribution of anticipatory alpha- and beta-band suppression to perceptual improvement with attention. J. Neurophysiol. 108, 2352-2362.

Wang, X.J., 2010. Neurophysiological and computational principles of cortical rhythms in cognition. Physiol. Rev. 90, 1195-1268.

Weiss, P.H., Rahbari, N.N., Lux, S., Pietrzyk, U., Noth, J., Fink, G.R., 2006. Processing the spatial configuration of complex actions involves right posterior parietal cortex: an fMRI study with clinical implications. Hum. Brain Mapp. 27, 1004-1014.

Wise, S.P., 1985. The primate premotor cortex, past, present, and preparatory. Ann. Rev. Neurosci. 8, 1-19.

Womelsdorf, T., Valiante, T.A., Sahin, N.T., Miller, K.J., Tiesinga, P., 2014. Dynamic circuit motifs underlying rhythmic gain control, gating and integration. Nat. Neurosci. 17, 1031-1039.

Wyart, V., Tallon-Baudry, C., 2008. Neural dissociation between visual awareness and spatial attention. J. Neurosci. 28, 2667-2679.

Yuval-Greenberg, S., Tomer, O., Keren, A.S., Nelken, I., Deouell, L.Y., 2008. Transient induced gamma-band response in EEG as a manifestation of miniature saccades. Neuron 58, 429-441.

Zaepffel, M., Trachel, R., Kilavik, B.E., Brochier, T., 2013. Modulations of EEG beta power during planning and execution of grasping movements. Plos One 8, e60060.

Zarka, D., Cevallos, C., Pétieau, M., Hoellinger, T., Dan, B., Chéron, G., 2014. Neural rhythmic symphony of human walking observation, Upside-down and uncoordinated condition on cortical theta, alpha, beta and gamma oscillations. Front. Syst. Neurosci. fnsys. 2014, 00169.

Zhang, Y., Wang, X., Bressler, S.L., Chen, Y., Ding, M., 2008. Prestimulus cortical activity is correlated with speed of visuomotor processing. J. Cogn. Neurosci. 20, 1915-1925.

Zumer, J.M., Scheeringa, R., Schoffelen, J.-M., Norris, D.G., Jensen, 0, 2014. Occipital alpha activity during stimulus processing gates the information flow to objectselective cortex. Plos Biol. 12, e1001965. 